This is a self-archived version of an original article. This version may differ from the original in pagination and typographic details.

Author(s): Kari, Tuomas; Salo, Markus; Frank, Lauri

Title: Role of situational context in use continuance after critical exergaming incidents

Year: 2020

Version: Accepted version (Final draft)

Copyright: (c) 2019 John Wiley \& Sons Ltd

Rights: In Copyright

Rights url: http://rightsstatements.org/page//nC/1.0/?language=en

Please cite the original version:

Kari, T., Salo, M., \& Frank, L. (2020). Role of situational context in use continuance after critical exergaming incidents. Information Systems Journal, 30(3), 596-633.

https://doi.org/10.1111/isj.12273 
This is the accepted manuscript -version. Final published version:

Kari, T., Salo, M., \& Frank, L. (2020) Role of situational context in use continuance after critical exergaming incidents. Information Systems Journal, 30(3), 596-633.

https://doi.org/10.1111/isj.12273

\title{
Role of Situational Context in Use Continuance After Critical Exergaming Incidents
}

\begin{abstract}
Use continuance is crucial in terms of information systems (IS) success. Previous research has shown that situational context can be central for IS use continuance but has paid limited attention to its specific characteristics. Furthermore, the link between situational context and use continuance has remained unexplored in the novel area of "exergames," which are defined as digital games requiring physical effort from the player that determines the outcome of the game. Studying exergames is deemed important due to their potential in providing health benefits for users, revenues for providers, and well-being for societies. However, their potential remains unreached because users tend to discontinue usage after their initial experiences. To address these gaps, we investigate the relationships between specific situational characteristics and use continuance after critical exergaming incidents, in which the user has an exceptionally positive or negative experience. To do this, we quantitatively and qualitatively examined 461 actual critical exergaming incidents. Our findings provide a greater understanding of IS use continuance by revealing new knowledge about the relationships between specific situational characteristics (i.e., purpose of use, type of gaming platform, social setting, place, and exertion level) and use continuance. We also offer explanations for these relationships, thus providing a first understanding of the previously unmapped area of how users behave situation-dependently after critical exergaming incidents. Thus, we contribute both to the general IS continuance literature as well as to the specific area of exergaming. The context specificity of our study matches the calls for heavily contextualized IS research.
\end{abstract}

Keywords: Information Systems, Use Continuance, Situational Context, Exergaming, Digital Games, Critical Incident Technique 


\section{INTRODUCTION}

"Use continuance" refers to whether a user continues to use a particular information systems (IS) product or service after its initial adoption (Bhattacherjee, 2001; Bhattacherjee \& Lin, 2015). Use continuance is highly important in terms of IS success (Bhattacherjee, 2001; Bhattacherjee \& Lin, 2015) and can be critical for the survival of IS providers (Hong, Thong, \& Tam, 2006). Despite the importance of studying use continuance, IS research has so far primarily focused on adoption and the initial phase of use (Bagayogo, Lapointe, \& Bassellier, 2014; Turel, 2015), and it has provided only limited insight into the detailed characteristics of post-adoptive IS use continuance (Bagayogo et al., 2014).

Use continuance and discontinuance of IS is influenced by users' single-use experiences (Cenfetelli, 2004; Serenko, 2006; Salo \& Frank, 2017). Some single-use experiences are more influential than are others; exceptionally influential single-use experiences, which a person "perceives or remembers as unusually positive or negative," are defined as "critical incidents" (Edvardsson \& Roos, 2001, p. 253). Concerning IS usage, critical incidents have been examined in different domains, from email to mobile services (e.g., Meuter, Ostrom, Roundtree, \& Bitner, 2000; Serenko \& Turel, 2010; Salo \& Frank, 2017). Previous IS-related studies provide interesting findings concerning critical incidents but shed less light on why users continue or discontinue usage after critical incidents.

One central aspect that differentiates critical incidents and can potentially influence use continuance is the situational use context. Previous studies have shown that situational context is central to use continuance for many types of IS (Liang \& Yeh, 2011; Venkatesh, Thong, Chan, Hu, \& Brown, 2011; Salo \& Frank, 2017), and developing a deeper understanding of the contextual characteristics of IS usage has been deemed desirable (Burton-Jones \& Gallivan, 2007; Burton-Jones \& Volkoff, 2017). However, in many previous studies, situational context has been treated as a single abstract construct. Therefore, there is a general gap in IS research regarding the relationships between specific situational characteristics and use continuance. In the present study, we provide a greater understanding of IS use continuance by conducting an exploratory study to uncover the relationships between specific situational characteristics and use continuance after critical incidents.

Digital games comprise an emerging form of IS, which has drawn growing attention from IS researchers and practitioners such as technology giants, software developers, and investors (Altinkemer \& Shen, 2008; Hamari \& Keronen, 2017). This has led to digital games becoming one of the most popular entertainment mediums in the world and arguably the largest form of leisure IS (Hamari \& Keronen, 2017). Hence, studying digital games addresses the calls made by Liu, Li, and Santhanam (2013, p. 122)—who stated: "We hope that our study findings and the proposed research framework will jump-start IS research on digital games"- 
and Lowry, Gaskin, Twyman, Hammer, and Roberts (2013, p. 618)—who stated: "[hedonicmotivation systems (HMS)] has made it into the elephant in the room for IS research. Given the serious global, economic, and organizational consequences of HMS, it is time for IS researchers to consider HMS as seriously as they do organizational systems."

Of the many types of digital games, our study focuses on exergames. "Exergames" are defined as digital games requiring physical effort from the player in order to play the game and where the player's physical effort determines the outcome of the game (Mueller et al., 2011; Kari \& Makkonen, 2014). We study exergames for three particular reasons:

(1) Exergames have unique characteristics and can be used in several different situational contexts. They are also an example of novel ubiquitous IS, which have "woven themselves into the very fabric of everyday life" and have "important implications for research in information systems" (Vodanovich, Sundaram, \& Myers, 2010, p. 711).

(2) Studying exergaming can be considered essential for several stakeholders. Exergames have potential in providing health benefits for their users, revenues for the providers, and well-being for societies. Exergaming is promising in terms of finding new ways to motivate people to do more physical activity and, subsequently, to fight the problems associated with a sedentary lifestyle, which are becoming increasingly prevalent in our society.

(3) Although exergaming has gained increasing attention among academic researchers (Maddison et al., 2013; Limperos \& Schmierbach, 2016), prior research has been dominated by a device-centric perspective instead of a user-centric perspective. This is a crucial gap in research because the potential of exergames remains unreached, as users of exergames tend to discontinue or diminish use after their initial experiences (Barnett, Cerin, \& Baranowski, 2011; Peng, Crouse, \& Lin, 2013; Maloney et al., 2015).

In the present study, we have examined 461 actual critical incidents of exergaming collected using the critical incident technique (CIT) and have analyzed these using quantitative statistical analysis. We have also conducted an additional qualitative content analysis to provide explanations for the statistical findings. The CIT fits the purpose of our study because this method is suitable for collecting users' real-life experiences of novel phenomena, it focuses on influential experiences, it enables highly contextualized information, and it can be used to link single experiences with behavioral outcomes (Meuter et al., 2000; Gremler, 2004; Gogan, McLaughlin, \& Thomas, 2014).

The contribution of our study is twofold: the findings contribute to the general IS use continuance literature as well as to the specific area of exergaming. First, based on the empirical findings, we provide a greater understanding of IS use continuance by investigating the role of situational context in use continuance after critical incidents. Considering the general shift toward ubiquitous IS (which are used in various kinds of situational contexts that potentially influence use continuance) (Yoo, 2010), our contribution yields fresh insights 
because, in previous studies on IS continuance, stationary technologies have outnumbered ubiquitous technologies as the system under investigation. Indeed, scholars are encouraged to explore the "poststationary" world of IS (Hedman, Bødker, Gimpel, \& Damsgaard, 2018, p. 18). We also shed light on the utilitarian and hedonic motivations of use, which have been deemed to deserve a more prominent place in IS research (Lowry et al., 2013; Wu \& Lu, 2013).

Second, we contribute to the area of exergaming and extend the theoretical understanding of the relationships between specific situational characteristics (i.e., purpose of use, type of gaming platform, social setting, place, and exertion level) and exergaming use continuance. We also offer explanations for the recognized relationships providing a first understanding of the previously unmapped area of how users behave situation-dependently after critical exergaming incidents.

The present study, being conducted in the specific area of exergaming, is highly contextualized. Such contextualization refers to identifying characteristics of the particular context under investigation and incorporating them in the research design (Davison \& Martinsons, 2016; Breward, Hassanein, \& Head, 2017). As contextualized studies take the specifics of IS use into account, they can promote the accuracy and relevance of the research findings (Breward et al., 2017), benefit practice by providing empirical insights (Burton-Jones \& Volkoff, 2017), extend extant theoretical knowledge (Davison \& Martinsons, 2016), and be helpful in better aligning IS use theorizations with how IS are actually employed in real-life circumstances (Ortiz de Guinea \& Webster, 2013). If the context is left unexamined, the findings can accordingly be inadequate (Whetten, 2009; Breward et al., 2017). As a result, IS researchers have called for "theories that focus on a specific context" because they "are considered to be vital in providing a rich understanding of a focal phenomenon and to meaningfully extend theories" (Venkatesh, Thong, \& Xu, 2012, p. 158). Our study aims to follow these calls and justifications by focusing on users' real-life experiences of exergaming and identifying their situational characteristics linked to use continuance.

As practical implications, we propose insights for exergame providers by suggesting different actions and aspects that would be valuable to consider in the design and development process and in increasing the life cycles of the games. We also highlight the critical incident types, along with their situational characteristics that are particularly meaningful for users, and provide suggestions for how the providers of exergames and other IS could achieve or avoid these critical incidents.

\section{RELATED RESEARCH AND BACKGROUND}

In this section, we first discuss use continuance literature to pinpoint a relevant research gap. As our study is conducted in the specific context of exergaming, we continue by reviewing 
previous research on exergaming to present potential benefits of exergaming research and demonstrate that there is a lack of knowledge about exergame use continuance. As we set our focus on the most influential experiences, we review studies on critical incidents related to IS. Finally, we draw from the previous literature that has examined situational context to build a framework for our exploratory study.

\subsection{Use continuance}

Use continuance (or continued use) is one of the most widely recognized potential postexperience behaviors after a product or service experience (Zeithaml, Perry, \& Parasuraman, 1996; Meuter et al., 2000; Holloway \& Beatty, 2008; Turel, 2015). Use continuance is normally considered a valuable behavior from the vendor or service provider's viewpoint because it often directly influences the creation and maintenance of customer relationships. Accordingly, use discontinuance is considered an unwanted behavior (Zeithaml et al., 1996). Therefore, IS providers can improve their odds for achieving success by maximizing use continuance and minimizing use discontinuance (Bhattacherjee, 2001; Bhattacherjee \& Lin, 2015).

Even though interest in IS use continuance has grown, previous research has not provided sufficient insight into the details of post-adoptive IS use continuance (Bagayogo et al., 2014). Also, as the eventual success of IS is less dependent on their initial adoption than on their continued use (Bhattacherjee, 2001), it is important to conduct more research on use continuance.

Previous research has already provided sufficient knowledge about some factors that influence IS use continuance, such as satisfaction and usefulness (Bhattacherjee, 2001), relationship commitment and trust (Vatanasombut, Igbaria, Stylianou, \& Rodgers, 2008), attitude and switching cost (Hong, Kim, \& Lee, 2008), and reasoned action, experiential response, and habitual response (Bhattacherjee \& Lin, 2015). However, there is insufficient knowledge about the impact of situational context, even though it has been proven to be relevant and important for use continuance (Liang \& Yeh, 2011; Venkatesh et al., 2011; Salo \& Frank, 2017). In the area of exergaming, the research investigating use continuance is literally non-existent. Studying the role of situational context in use continuance is highly essential, especially in currently emerging ubiquitous IS, such as exergames, that are used in various kinds of situational contexts that potentially influence use continuance.

\subsection{Exergaming research}

The rapid advance of information technology (IT) has impacted various IS areas and facilitated the development of entirely new innovations. One IS area that has undergone constant development is digital gaming. For example, the recently trending Pokémon GO exergame has attracted more than 100 million active users after its launch in 2016 (Forbes, 2018). Correspondingly, a recent stream of research in top-tier IS journals has emphasized the 
importance of studying digital games and laid the groundwork for such in-depth study (Van der Heijden, 2004; Gerow, Ayyagari, Thatcher, \& Roth, 2013; Liu et al., 2013; Lowry et al., 2013; Lowry, Gaskin, \& Moody, 2015).

The development of digital gaming has facilitated completely new gaming concepts, such as exergames. Exergames (also known as active videogames or exertion games) refer to digital gaming concepts that combine gaming with physical exertion. Following Kari and Makkonen (2014, p. 2), in the present study, "exergaming" is defined as "a form of digital gaming requiring aerobic physical effort-exceeding sedentary activity level and including strength-, balance-, or flexibility-related activity—from the player that determines the outcome of the game." Thus, exergames include digital games in which the physical exertion aspect is fundamentally present through game play or game mechanics. A well-known example of exergames is Nintendo's Wii Sports and its sequels, in which the player uses a motion controller to mimic real-life sports and control the on-screen actions. For a wide variety of examples of exergames, we refer the reader to Mueller, Khot, Gerling, and Mandryk (2016). As an example of what would not constitute an exergame or exergaming activity, playing Angry Birds while walking would not be considered exergaming, as the game itself does not require physical effort to be played.

Exergames have a ubiquitous and dual-purposed nature (Hong \& Tam, 2006): the purpose of use can be hedonic such as entertainment or utilitarian such as promoting physical activity (e.g., Osorio, Moffat, \& Sykes, 2012; Kari \& Makkonen, 2014; Baranowski, 2017), or even both at the same time (e.g., Berkovsky, Coombe, Freyne, Bhandari, \& Baghaei, 2010; Finco \& Maass, 2014). This, as presented in Hamari \& Keronen (2017, p. 136), makes exergames unique in a way that "rather than the purposes taking turns, they may exist at the same time." Exergames can also be played at different physical exertion levels (e.g., Whitehead, Johnston, Nixon, \& Welch, 2010; Wittman, 2010; Peng et al., 2013), which according to U.S. Department of Health and Human Services (2008) can be categorized into light (i.e., no sweating or accelerated breathing), moderate (i.e., some sweating and accelerated breathing), and vigorous (i.e., strong sweating and accelerated breathing). Several studies that have investigated the exertion levels of exergaming have applied this categorization (e.g., Barnett et al., 2011; LeBlanc et al., 2013; Peng et al., 2013; Kari, 2014). Exertion level can be influenced by different factors such as physical characteristics, experience, and motivation (Whitehead et al., 2010). For example, some users engage in heavy workouts with exergames whereas others play them to engage in stretching exercises.

Social setting forms an important aspect of exergaming (Suhonen, Väätäjä, Virtanen, \& Raisamo, 2008; Peng \& Crouse, 2013; Marker \& Staiano, 2015) and several exergames provide the possibility to play either alone or with others in the same physical space or in separate physical spaces over a network (Osorio et al., 2012; Maddison et al., 2013; Peng \& 
Crouse, 2013). Exergames can be used in various places (Lieberman et al., 2011; Baranowski, Maddison, Maloney, Medina, \& Simons, 2014) and can be played on different platforms (Kari \& Makkonen, 2014), the most popular being the commercially available console-based devices (e.g., Nintendo's Wii and Switch, Microsoft's Xbox, and Sony's PlayStation) and mobile-based devices (i.e., mobile phones and tablets) (Chamberlin \& Maloney, 2013). Console-based exergames (e.g., dance games) can be characterized as games that are played in front of a television set, whereas mobile-based exergames (e.g., Pokémon GO) are usually played outdoors in a much bigger playing area. Certain mobilebased exergames can also be played indoors, as they are designed to utilize the different sensors of mobile devices for game play and movement tracking in a smaller space. Other platform types include, for example, those embedded into exercise equipment or those in arcades or interactive outdoor playgrounds (Chamberlin \& Maloney, 2013; Kari, 2015; Reidsma \& van Delden, 2018).

Even though these characteristics may individually apply also to other types of IS, the combination of them makes the context of exergaming one of a kind. Further, compared to other digital games, exergames are unique in the way that they shift the notion of digital games from imagined computing to experiential computing. For example, whereas Yoo (2010, p. 218) places traditional digital games under the category of an "imagined view of computing," where the technology becomes the alter ego, exergames better fall under the concept of "experiential computing," which emphasizes the notion of the embodiment relationship between technology, world, and people, generating various situational contexts of use.

Although technological advancement has provided industries and people around the globe with huge potential benefits, it has come at the major cost of replacing physical activity with physical inactivity and has thus contributed to a worldwide epidemic of chronic diseases (Hallal et al., 2012). As the health consequences of physical inactivity and the health benefits of physical activity are well established (e.g., Warburton, Nicol, \& Bredin, 2006; World Health Organization, 2010; Lee et al., 2012), there is certainly a demand for IS that could advance desirable health behaviors. Although digital gaming in general has been perceived to increase the sedentary time of individuals, gaming can also act as a medium to promote health (Nah, Eschenbrenner, Zeng, Telaprolu, \& Sepehr, 2014) and an active lifestyle (Tan, Kumar, \& Ralph, 2016). Moreover, due to the motivational aspects of digital games, they are suitable for promoting specific behaviors (Monu \& Ralph, 2016).

Exergames, in particular, have been proposed as a possible catalyst for increasing physical activity (e.g., Papastergiou, 2009; Krause \& Benavidez, 2014; Höchsmann, Schüpbach, \& Schmidt-Trucksäss, 2016) and replacing sedentary behaviors (e.g., Baranowski et al., 2014; Kari, 2014; Barkley, Lepp, \& Glickman, 2017). They can even realize this without requiring the players to have a thorough understanding of fitness (Bogost, 2005). 
Exergames were originally designed and developed as an entertainment medium, but later on, members of public health institutions and the game providers themselves saw their utilitarian potential to provide new ways for people to be physically active. This has resulted in exergames not just being sold for profit but also designed as a means to improve health.

The allure of digital technologies in general is that they are readily distributable and have the realistic potential to reach large populations. This, together with the appeal and widespread familiarity of video gaming, adds to the potential of exergaming to promote a healthier lifestyle (Maddison et al., 2013). Thus, exergames can foster what Liu, Santhanam, and Webster (2016) refer to as "meaningful engagement"- that is, they can provide both experiential and instrumental outcomes.

Exergames have become increasingly popular in recent years and are, at the same time, a subject of growing interest among academic researchers. There has been a wide diversity of studies concerning exergaming across different disciplines. However, most of the previous studies on exergaming have focused on a device-centric perspective, such as the games and gaming devices themselves or their design (e.g., Mueller \& Isbister, 2014; Laine \& Suk, 2016; Mueller, Gibbs, Vetere, \& Edge, 2017), on the potential of these games to promote physical activity or physical fitness (e.g., Baranowski et al., 2012; LeBlanc et al., 2013; Marquet, Alberico, \& Hipp, 2018), or on their possibilities in assisting with ailments, disorders, healthy aging, or rehabilitation (e.g., Howcroft et al., 2012; Taylor \& Griffin, 2015; Donath, Rössler, \& Faude, 2016). Appendix F presents an overview of previous research.

Although the number of studies conducted from a user-centric perspective has increased recently (e.g., Lin, Wang, \& Chou, 2012; Osorio et al., 2012; Hoda, Alattas, \& El Saddik, 2013; Kari \& Makkonen, 2014; Adam \& Senner, 2016; Limperos \& Schmierbach, 2016; Van Nguyen et al., 2016; Joronen, Aikasalo, \& Suvitie, 2017), there is a dearth of understanding on the usage aspects of these games. In general, studies have consistently stated that exergaming is a fun and enjoyable activity (e.g., Gao, Zhang, \& Stodden, 2013; Joronen et al., 2017). Hoda et al. (2013) found that exergames can help in transforming boring exercises into entertaining ones, which subsequently increases players' motivation to continue exercising. Van Nguyen et al. (2016) found that exergaming can improve attitudes and intentions towards other forms of exercise but only among frequent exercisers, not among infrequent exercisers. Kari and Makkonen (2014) found that descriptive subjective norm, perceived behavioral control, and attitude are important drivers behind the intention to use exergames. They also measured attitude toward the intention to use exergames in relation to behavioral beliefs on the outcomes of usage and found that it is driven more by the hedonic than utilitarian aspects of exergaming. This finding is in line with that of Lin et al. (2012), who found that perceived exercise utility and perceived enjoyment influence behavioral intention, but the intention to use exergames is influenced more by perceived enjoyment than perceived 
exercise utility. Similarly, Adam and Senner (2016) found that fun is more important than utility in driving the long-term motivation to play exergames. Yet, they also suggested that a lack of fun is not the main reason people stop playing.

Osorio et al. (2012) found that the perceived exertion level while playing, enjoyment perceptions, social setting, and feeling after a gaming session influence the use of exergames. Limperos \& Schmierbach (2016) found that player performance during exergaming is related to psychological experiences of autonomy and presence (i.e., immersion and intensity): players who perform well in an exergame feel more autonomous and greater presence, which subsequently leads to greater enjoyment. Further, they found presence and enjoyment to be the strongest predictors of intention to use an exergame in the future. Joronen et al. (2017) conducted a systematic review of the nonphysical effects of exergames. They found exergaming to have mostly positive effects on self-concept, situational interest and motivation, enjoyment, psychological and social well-being, and different learning experiences.

Although some of the above-presented studies touch on the subject of the future intentions of exergames usage, in total they are few and do not explain use (dis)continuance. This remains a critical and pertinent issue (Kari, 2017), as several studies (e.g., Barnett et al., 2011; Peng et al., 2013; Maloney et al., 2015) have reported a decrease in users' exergaming play after their initial experiences but have not reported the apparent reasons for this. Our focus can be considered as a sequel to these studies: we take an IS research approach to extend their initial insights by exploring use continuance after critical exergaming incidents.

\subsection{Critical incident research}

Use continuance is influenced by users' critical incidents with IS (Cenfetelli, 2004; Serenko, 2006; Salo \& Frank 2017). As an example of a positive critical incident, an exergame could enable the discovery of a new, fun way of doing an exercise or could provide a strong feeling of achieving a highly desired goal in the game. As an example of a negative critical incident, a person could lose interest because of unusually poor functionality or break something while playing. Examples of actual critical incidents gathered from the respondents of our empirical study are presented in Appendix A.

Researchers have justified a focus on critical incidents for several reasons (Salo \& Frank, 2017): critical incidents influence user perceptions of products and services as well as future usage (Flanagan, 1954; Edvardsson \& Strandvik, 2000; Serenko, 2006). Such a focus aids researchers in maintaining rigor and relevance by examining detailed accounts of actual usage instead of hypothetical scenarios (Serenko \& Turel, 2010). Overall, critical incidents are generally powerful in terms of human behavior (Flanagan, 1954; Thomas \& Bostrom, 2010).

Critical incidents have been a popular topic in the field of service research (for an overview, see Gremler, 2004). Concerning IS usage, studies have examined critical incidents 
in mobile services and applications (Gummerus \& Pihlström, 2011; Salo, Olsson, Makkonen, Hautamäki, \& Frank, 2013; Salo \& Frank, 2017), online shopping (Holloway \& Beatty, 2008), online transactions (Massad, Heckman, \& Crowston, 2006), self-service technologies (Meuter et al., 2000), online travel services (Serenko \& Stach, 2009), email (Serenko, 2006; Serenko \& Turel, 2010), websites (Sweeney \& Lapp, 2004), electronic-reverse auctions (Hackney, Jones, \& Lösch, 2007), and social networking sites (Maier, Laumer, Eckhardt, \& Weitzel, 2015). However, with exergames, critical incidents and their effects have not yet been studied at all. Further, to our best knowledge, only a few studies (Meuter et al., 2000; Serenko, 2006; Serenko \& Stach, 2009; Serenko \& Turel, 2010; Salo \& Frank, 2017) to date have investigated critical incidents in connection with post-experience behaviors. These studies demonstrate that certain positive or negative critical incidents can indeed influence user behaviors. However, apart from the study by Salo and Frank (2017), the studies provide no insights on the relationships between situational context and use continuance.

\subsection{Situational context research}

Previous research has proposed that the varying situational context can influence and shape the user's behavioral responses (e.g., use continuance) after a product or service experience (Mehrabian \& Russell, 1974; Xiao \& Benbasat, 2011). These assumptions are supported by previous IS use research, which has shown that situational context can be important for use (e.g., Van der Heijden, Ogertschnig, \& Van der Gast, 2005; Hong \& Tam, 2006; Liang \& Yeh, 2011; Liu \& Li, 2011; Venkatesh et al., 2011; Yang, Lu, Gupta, \& Cao, 2012; Constantiou, Lehrer, \& Hess, 2014; Salo \& Frank, 2017). Some of these studies have presented a direct relationship between the two. As situational context can include any "information that can be used to characterize the situation of an entity (a person, place, or object)" (Dey, 2001, p. 5), the relationship can be based on various situational characteristics such as social setting, place, and technology type. All these situational characteristics may have a positive or negative influence on IS use (Liu \& Li, 2011; Yang et al., 2012; Salo \& Frank, 2017).

Previous studies (cf., Jumisko-Pyykkö \& Vainio, 2010) have repeatedly identified five essential situational characteristics: task context, technical context, social context, physical context, and temporal context. Similar to Jumisko-Pyykkö and Vainio (2010), Maguire (2001) suggests that the main aspects of context are: user goals and characteristics, technical environment, social environment, physical environment, and tasks. Although Maguire (2001) and Jumisko-Pyykkö and Vainio (2010) have provided a framework for situational context and its boundaries, many previous use continuance studies involving situational context have not utilized such frameworks but instead, for instance, have combined several aspects of situational context into one abstract construct (or have employed only limited aspects of situational context). This means that they have combined (and measured) specific situational 
characteristics, such as place and social setting, as a single construct named "use context." Thus, they do not sufficiently explain the influence of specific situational characteristics.

Drawing from Maguire (2001) and Jumisko-Pyykkö and Vainio (2010), as well as exergaming literature, we applied five essential and specific situational characteristics in which exergames can be played and that are essential parts of the usage experience. The first four of these are purpose of use (task context), type of gaming platform (technical context), social setting (social context), and place (physical context). Thus, we link these situational characteristics to the specific context of exergaming. In addition, we identified and selected a unique characteristic-exertion level-which is a highly important aspect relating to exergaming (cf., Kari, 2014). We elaborate on the five characteristics in Table 1.

TABLE 1 Summary of the situational characteristics related to exergaming

\begin{tabular}{|c|c|c|}
\hline $\begin{array}{l}\text { Situational } \\
\text { characteristics }\end{array}$ & Description & Categories \\
\hline Purpose of use & $\begin{array}{l}\text { The underlying reason why the user has taken up the } \\
\text { action of using something - in this case, exergames. } \\
\text { Prior research: Purpose has been shown to have } \\
\text { implications for IS use (e.g., Wakefield \& Whitten, } \\
\text { 2006; Deng, Turner, Gehling, \& Prince, 2010). }\end{array}$ & $\begin{array}{l}\text { Hedonic } \\
\text { Utilitarian } \\
\text { Both simultaneously }\end{array}$ \\
\hline $\begin{array}{l}\text { Type of gaming } \\
\text { platform }\end{array}$ & $\begin{array}{l}\text { The technology that is used to play the exergame. } \\
\text { Prior research: Technology platform and device have } \\
\text { been identified to influence IS use (e.g., Maguire, } \\
\text { 2001; Jumisko-Pyykkö \& Vainio, 2010). }\end{array}$ & $\begin{array}{l}\text { Console-based } \\
\text { Mobile-based } \\
\text { Other platforms }\end{array}$ \\
\hline Social setting & $\begin{array}{l}\text { The social setting in which the gaming takes place. } \\
\text { Prior research: Sociability has been shown to be a } \\
\text { contributing component to IS use (e.g., Junglas, Goel, } \\
\text { Abraham, \& Ives, 2013). }\end{array}$ & $\begin{array}{l}\text { Individual setting } \\
\text { Group setting }\end{array}$ \\
\hline Place & $\begin{array}{l}\text { The surrounding environment in which the gaming } \\
\text { occurs. } \\
\text { Prior research: Place has been suggested to influence } \\
\text { IS use (e.g., Coursaris \& Kim, 2011; Lee et al., 2005). }\end{array}$ & $\begin{array}{l}\text { Home } \\
\text { Outdoor } \\
\text { Public setting } \\
\text { Friend's home }\end{array}$ \\
\hline Exertion level & The physical exertion level that the game is played at. & $\begin{array}{l}\text { Light } \\
\text { Moderate } \\
\text { Vigorous }\end{array}$ \\
\hline
\end{tabular}

The selected situational characteristics are extensive but, of course, not all-inclusive. Previous literature has identified other influential characteristics of the situational context-for example, emotional state (Lee, Kim, \& Kim, 2005) and price (Venkatesh et al., 2012) —that can, in turn, influence general IS use. Also, we have not included or investigated the temporal context documented in Jumisko-Pyykkö and Vainio (2010) because, unlike with all the other included situational characteristics, previous exergaming literature does not identify distinct categories for it. This could be due to the abstract nature of the temporal context compared to the other situational characteristics. In principle, information about context is limitless (Chávez, Ide, \& Kirste, 1999), with "hundreds of potential context characteristics affecting the 
experience," such as "sunshine or grandma following the actions" (Roto, Väätäjä, JumiskoPyykkö, \& Väänänen-Vainio-Mattila, 2011, p. 91). Therefore, our approach was to anchor the present study in the frameworks established by Maguire (2001) and Jumisko-Pyykkö and Vainio (2010). By drawing from these and the exergaming literature, we set conceptual boundaries surrounding the concept of situational context in the present study. Thus, we have targeted the essential characteristics by centering our focus on those characteristics that (1) were identified as essential in previous literature (Jumisko-Pyykkö \& Vainio, 2010; Maguire, 2001), (2) are assumed to be related to user behaviors, (3) are applicable to exergaming, and (4) are capable of being influenced by the developers. Hence, we consider the selected characteristics to include the most important ones that are present when the actual exergaming experience occurs and that are the most essential to understand.

\subsection{Research framework}

Based on our aforementioned justifications, the proposed research framework (Figure 1) draws from the extant literature: we specified the generic model of Jumisko-Pyykkö and Vainio (2010) and Maguire (2001) with the help of exergaming literature. The framework contains the selected five situational characteristics that are assumed to have relationships with use continuance: purpose of use, type of gaming platform, social setting, place, and exertion level.

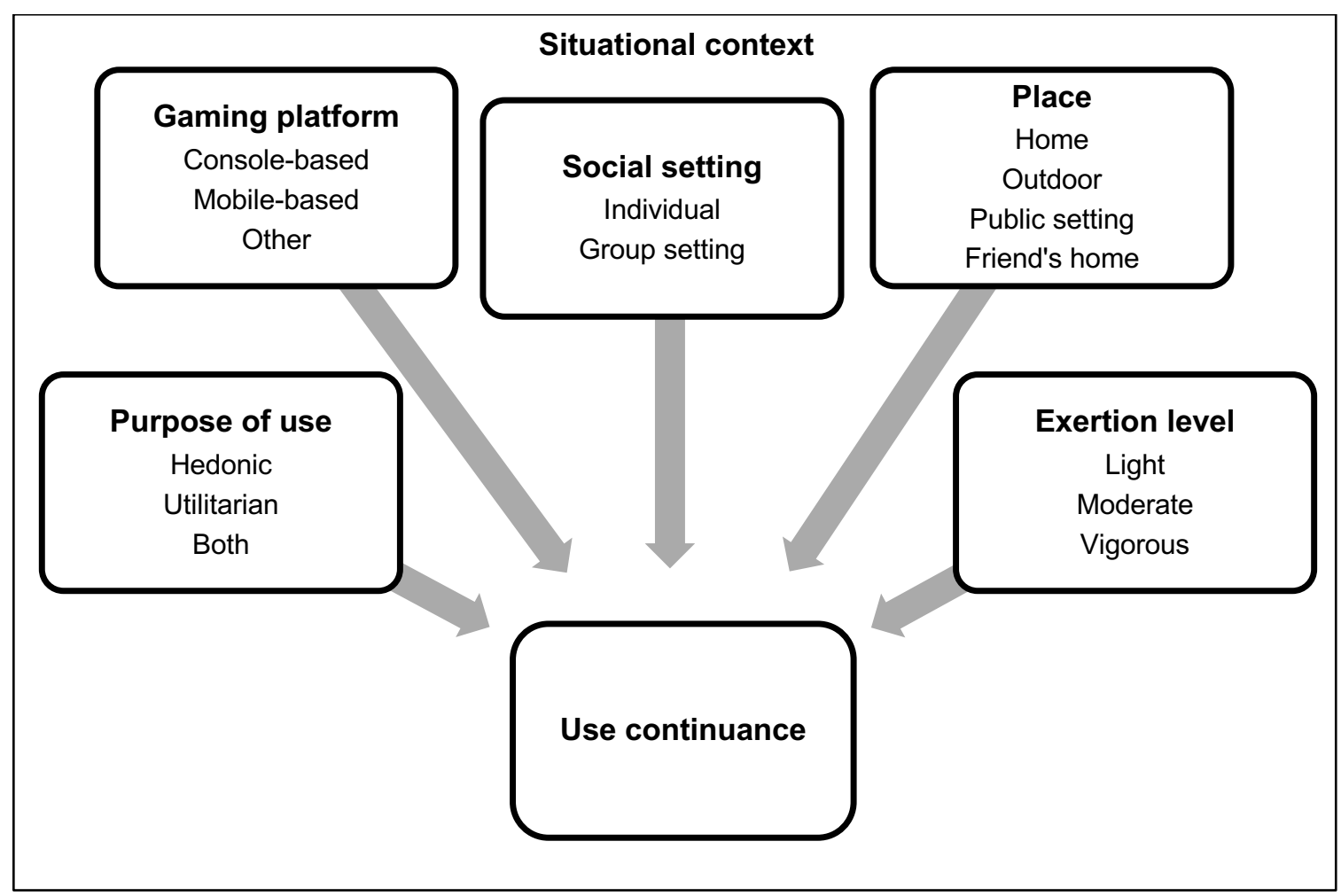

FIGURE 1 The proposed framework for explaining the relationships between situational context and use continuance 
As the context of the present study is exergaming, the framework is hence intended to be context specific. This contrasts with more abstract models and theories, such as the IS success model (DeLone \& McLean, 2003) and the expectation-confirmation model (Bhattacherjee, 2001), which are intended to explain the acceptance and use of technology on a more general level. Our approach offers opportunities to gain a deeper understanding of user behaviors within a specific context, which is considered valuable for both theory and practice (Burton-Jones \& Straub, 2006; Venkatesh et al., 2012). To summarize, the present study explores the role of specific situational characteristics in use continuance after critical exergaming incidents and explains this with the help of empirical evidence.

\section{METHOD}

Answering our research aims required detailed data about users' real-life experiences and post-experience behaviors in the context of exergames. Therefore, we chose to conduct our study using the CIT (Flanagan, 1954). This approach was considered appropriate because of its usefulness in providing highly contextualized records of individuals' actual, influential incidents with IS and their consequential behavioral intentions (Gogan, et al., 2014; Gremler, 2004; Meuter et al., 2000).

\subsection{Critical incident technique}

CIT is a well-established technique that involves "a set of procedures" (Flanagan, 1954, p. 327 ) "to collect, content analyze, and classify observations of human behavior" (Gremler, 2004, p. 66). CIT allows respondents to describe the actual (positive or negative) incidents of IS use in their own words, and CIT questionnaires can include questions related to users' postincident behaviors (Meuter et al., 2000). CIT has been extensively applied across many different disciplines (Butterfield, Borgen, Amundson, \& Maglio, 2005) such as IS, organizational psychology, marketing, and other business disciplines (Gogan et al., 2014). However, CIT has not been applied in exergaming research before, although numerous studies have demonstrated CIT to be a credible method for studying human behavior (Gogan et al., 2014; Gremler, 2004).

Previous literature has identified four main justifications for using CIT. The first justification pertains to the use of CIT for exploring an undiscovered phenomenon in real life (Meuter et al., 2000; Gremler, 2004), which fits with our aim to pay attention to users' real-life experiences of the novel area of exergaming (rather than users' general opinions or hypothetical scenarios). Another justification for using CIT is its focus on important experiences (Gremler, 2004; Gogan et al., 2014; Oh \& Oh, 2017), which we want to examine because outstanding experiences have been found to be highly influential in terms of human behavior (Flanagan, 1954; Thomas \& Bostrom, 2010). The third justification for using CIT is the contextualized information it offers in the form of an accurate record of actual events 
(Gabbott \& Hogg, 1996; Grove \& Fisk, 1997; Klendauer, Berkovich, Gelvin, Leimeister, \& Krcmar, 2012). Finally, the fourth justification for using CIT is the aid it provides in uncovering links between different types of experiences and behaviors (Meuter et al., 2000; Serenko \& Stach, 2009; Salo \& Frank, 2017), which resonates well with the main aim of the present study.

\subsection{Study design, data collection, and measures}

The study design followed relevant guidelines for CIT studies presented by Gremler (2004) and Gogan et al. (2014). To obtain a solid number of critical incidents, we chose to collect data from Finnish consumers in a questionnaire format (c.f., Bitner, Booms, \& Tetreault, 1990; Meuter et al., 2000; Serenko \& Turel, 2010; Turner \& Reinsch, 2010). The (online) questionnaire was iteratively designed, as we aimed to establish content validity with the following procedures (Cui, Lai, \& Lowry, 2016; Menard, Warkentin, \& Lowry, 2018): First, when possible, we adapted the measures and instructions from previously validated and widely applied instruments. Second, we employed previous literature to cover a comprehensive set of situational characteristics related to IS and exergaming use. Third, we conducted a pre-test with five IS scholars who had experience studying topics related to IS use. Fourth, we ran a pilot questionnaire among 70 undergraduate students and provided space for them to give comments about the questionnaire. Based on the feedback from the pre-test and the pilot, we made a few minor modifications to the wording and structure of the questionnaire. The final questionnaire was then active for three months, from the beginning of February 2015 to the end of April 2015. We distributed the questionnaire by (1) posting a link on several Finnish discussion forums that focus on a variety of topics (e.g., sports, technology, gaming, parenting, seniors, economy) and audiences, (2) sharing the link on Facebook, and (3) sending invitation emails through different mailing lists meant for informative purposes. In order to motivate the respondents, we offered respondents who completed the questionnaire and submitted their email addresses the opportunity to take part in a raffle to win one of five gift cards.

We maintained elicitation clarity (Gogan et al., 2014) and the appropriateness of the respondents (Gremler, 2004) by asking only those respondents who had experience of playing exergames to report their critical incidents. In the instructions of the questionnaire, we described what were considered as exergames (following the definition by Kari \& Makkonen, 2014) and gave examples of them. To collect open-ended descriptions of critical incidents, we used the wording of several other prominent and widely cited CIT-related papers (e.g., Bitner et al., 1990; Johnston, 1995; Meuter et al., 2000), as follows: "think of a time when you had an outstandingly positive or negative experience [when using an exergame]." The respondents were first asked: "Was this a positive or a negative experience?." Inspired by previous CIT studies (e.g., Meuter et al., 2000; Serenko \& Turel, 2010; Salo \& Frank, 2017), we then asked a set of clarifying open-ended questions to let the respondents name the associated exergame 
and describe the incident in their own words: (1) "The game associated with the experience:"; (2) "Describe in as much detail as possible: what were you doing and what happened?"; (3) "What exactly caused the positivity/negativity of the experience?" (depending on whether the described incident was positive or negative); (4) "Why do you feel that this was a significant experience for you concerning exergaming?"; and (5) "As an outcome of the experience, how did you feel?."

The situational characteristics (i.e., purpose of use, type of gaming platform, social setting, place, and exertion level) were asked about using structured questions. The explicit structured questions enabled us to derive the situational characteristics directly from the respondents and, in this way, assumedly improved the accuracy of the findings. The full question items are presented in Appendix $C$ and Appendix $D$. The wording and questions from previous studies were translated from English into Finnish.

For use continuance, we measured the intended post-incident use continuance. The use continuance construct was operationalized and measured using three statements adapted and modified from validated instruments presented in previous studies (Mathieson, 1991; Bhattacherjee, 2001). The exact wording of the use continuance items depended on whether the respondent chose to describe a positive or a negative incident. We asked the respondents to rate statements about their consequential use continuance intentions for the exergame that were associated with the described incident. We used the traditional five-point Likert scale, including response options that ranged from "strongly disagree" to "strongly agree." The respondents also had a "no answer" option to reduce the likelihood of eliciting forced responses. Table 2 presents the statements, reference studies, and related Cronbach's alphas. The Cronbach's alpha values for each construct exceed the suggested minimum for exploratory research (0.7) (Nunnally \& Bernstein, 1994), which indicates the constructs can be considered reliable and internally consistent.

TABLE 2 Use Continuance: Construct Items, Reference Studies, and Cronbach's Alphas

\section{Construct Items for Use Continuance}

Use continuance (adapted from Mathieson, 1991; Bhattacherjee, 2001) with positive incidents, Cronbach's $\alpha=0.839$

As a consequence of the experience I just described, I wanted to...

... continue using the exergame in the future rather than discontinue its use.

... continue using the exergame in the future.

... discontinue using the exergame. (reverse coded)

Use continuance (adapted from Mathieson, 1991; Bhattacherjee, 2001) with negative incidents, Cronbach's $\alpha=0.932$

As a consequence of the experience I just described, I wanted to... discontinue using the exergame in the future rather than continue its use. discontinue using the exergame in the future. continue using the exergame. (reverse coded) 


\subsection{Study respondents}

We received a total of 1151 responses to our online questionnaire. Of the respondents, 468 $(40.7 \%)$ stated that they had used (more than tried) exergames and were asked more questions about exergames, including the questions related to critical incidents. The responses from these 468 individuals, with the exception of 7 responses that did not meet the inclusion criteria (presented in the Analysis section below), form the study sample and were used for the actual analysis $(\mathrm{N}=461)$.

Descriptive statistics of the whole sample of 1151 respondents as well as the subsample of the 461 respondents used for our study are presented in Table 3 , as advised by Gremler (2004). The mean age of the respondents was 36.1 years (SD $=14.2$ years) for the whole sample and 31.5 years $(S D=11.3$ years) for the study sample. The number of males and females was quite equal between the samples. In terms of age and gender distribution, the study sample is fairly close to the population of Finnish digital gamers (Mäyrä, Karvinen, \& Ermi, 2016) and thus was considered suitable for the present study.

TABLE 3 Descriptive Statistics of the Whole Sample and the Used Sub-sample

\begin{tabular}{lllll} 
& \multicolumn{2}{l}{ Whole sample (N = 1151) } & \multicolumn{2}{l}{ Study sample (N = 461) } \\
\hline Gender & $\mathbf{N}$ & $\%$ & $\mathbf{N}$ & $\%$ \\
$\quad$ Male & 592 & 51.4 & 233 & 50.5 \\
Female & 559 & 48.6 & 228 & 49.5 \\
Age & & & & \\
-19 years & 67 & 5.8 & 40 & 8.7 \\
20-29 years & 427 & 37.1 & 207 & 44.9 \\
30-39 years & 247 & 21.5 & 108 & 23.4 \\
40- years & 410 & 35.6 & 106 & 23.0 \\
Socioeconomic group & & & & \\
Student & 349 & 30.3 & 178 & 38.6 \\
Employed & 537 & 46.6 & 218 & 47.3 \\
Unemployed & 114 & 9.9 & 37 & 8.0 \\
Pensioner & 95 & 8.3 & 10 & 2.2 \\
Other & 56 & 4.9 & 18 & 3.9 \\
Has played exergames & & & & \\
Yes & 468 & 40.7 & 461 & 100 \\
No & 663 & 57.6 & 0 & 0 \\
N/A & 20 & 1.7 & 0 & 0 \\
\hline
\end{tabular}

\subsection{Analysis}

To ensure the quality of the empirical evidence, we followed guidelines from previous literature (Bitner et al., 1990; Gremler, 2004; Sweeney \& Lapp, 2004; Gogan et al., 2014) and determined criteria for whether respondents' critical incidents should be included in the present study: (1) The incident was required to be a single outstandingly positive or negative incident involving a specific exergaming event; (2) the incident was required to have a 
sufficient description; and (3) the incident had to include at least one answer to questions concerning post-experience use continuance. Out of the responses of the 468 respondents who stated that they had played exergames and reported a critical incident, 461 (331 positive and 130 negative) met the criteria and were included in the analysis, the critical incident itself being the unit of analysis. As suggested by Gremler (2004) and Gogan et al. (2014), we briefly describe the general data characteristics at the beginning of the Results section and provide illustrative data examples of both positive and negative critical incidents in Appendix A.

As respondents in CIT studies report different kinds of incidents, CIT can be applied to examine the relationships between the characteristics of different incidents and behavioral intentions (Meuter et al., 2000). More specifically, researchers can link the incidents' categorized characteristics to post-incident behaviors using statistical tests (Meuter et al., 2000). Thus, the collected data was quantitatively analyzed using the IBM SPSS Statistics 22 software. In our analysis, we followed the widely cited guidelines by Field (2013). To analyze the statistical significance of the differences between the situational characteristics and the post-experience use continuance, we calculated the mathematical means of the items for each construct and used independent-samples t-tests or one-way analysis of variance (ANOVA) tests to compare the means. A t-test was used for variables with two nominal categories and an ANOVA test was used for variables with three or more nominal categories. Combined with the ANOVA test, we used post-hoc tests for pair comparisons-either Tukey's HSD (when equal variances assumed) or Tamhane's T2 (when equal variances not assumed). In some cases, the assumption of homogeneity of variance was not met, and in these cases, we analyzed and reported the Welch's F-ratio. The "cannot say" responses to the situational characteristics questions were excluded from the analysis of that particular characteristic-for example, if a respondent was unable to state the exertion level of the incident, that response was excluded from the analysis of the exertion level. For all the performed tests, the level of significance was set to 0.05 .

To analyze the discriminant validity of the surveyed concepts, we did the following: First, although a correlation cannot be calculated for categorical variables, the Cramer's $\mathrm{V}$ statistic can be used to quantify their association in a similar way, and it is interpreted similarly (i.e., $0=$ no association, 1 = perfect association). We used this statistic to analyze the associations between the five situational characteristics (categorical variables). Second, we analyzed the correlations between the 15 categories of the situational characteristics. We did this by constructing dummy variables (0/1-variables) for each of the categories. In general, this investigation did not reveal any major issues with discriminant validity. First, the Cramer's $V$ values were all below 0.85 , a common cutoff for a too-high correlation (Shaffer, DeGeest, \& $\mathrm{Li}, 2016$, p. 96), suggesting acceptable discriminant validity using this metric. The strongest association between the five situational characteristics was between place and gaming 
platform: 0.67 , which is well below the 0.85 cutoff. Second, all but one of the correlation coefficients were below 0.85 , suggesting acceptable discriminant validity for all individual pairs of categories except one. Hence, we inspected this single high correlation in more detail. The strong correlation was between the characteristics "mobile" (gaming platform) and "outdoor" (place): 0.89 . Although this is a strong correlation that causes concern, the correlation is still quite far from perfect correlation. The high correlation arises because there is a conceptual overlap between "mobile" and "outdoor"-one typically needs to use a mobile platform to play a game outdoors. Shaffer et al. (2016, p. 96) also presented another cutoff of 0.90 ; the present correlation falls within that cutoff, indicating enough difference for these constructs to be useful as separate categories. The correlation matrices are available from the authors by request.

In addition to the quantitative statistical analyses, we carried out a qualitative content analysis for the incident descriptions, which were asked about using open-ended questions. When doing this, we applied Gremler's (2004) checklist for CIT content analytic studies and Sarker, Xiao, and Beaulieu's (2013) general guidelines for qualitative approaches. The aim was to find recurring themes in the statistically significant relationships found in the statistical analyses. Thus, we specifically focused on the characteristics of the incidents that were more likely to have led to positive or negative behaviors, instead of searching for the whole array of explanations. As the analysis focused on discovering explanatory themes instead of providing input for statistical tests, we did not conduct explicit coding. Explicit coding is not required in all qualitative analyses (Sarker et al., 2013). The qualitative analysis process can be presented through the following phases, adapted from Gremler's (2004) guidelines: (1) We read and reread the incident descriptions to recognize common and explanatory tendencies for the statistically significant relationships and discussed the findings together and with other scholars; (2) based on the incident descriptions and the recognized tendencies, we identified recurring themes for each of the statistically significant relationships; (3) based on the recurring themes, we developed a classification scheme, which we discussed with other scholars; and (4) we created descriptions for each category. The classification and the category descriptions from the qualitative analysis are presented in more detail in Appendix $B$.

\section{RESULTS}

In total, our analysis included 461 reported critical incidents, out of which 331 (71.8\%) were positive and $130(28.2 \%)$ were negative. The incidents were related to a variety of different games across different gaming platforms. The most popular platform was console-based (83.6\%), followed by mobile-based $(10.5 \%)$ and other platforms $(5.9 \%)$. The most popular console-based exergame titles were Wii Sports (21\%) and Wii Fit (15\%). Various dancing 
games were also popular, accounting for about $16 \%$ of all the console-based exergame titles. Among mobile-based exergames, Zombies, Run! (27\%) was the most popular game.

A t-test was also conducted to compare the use continuance after positive and negative critical incidents. In general, the results show that users were indeed more likely to intend to continue usage after a positive $(M=4.29, S D=0.79)$ than a negative $(M=2.95, S D$ $=1.42)$ incident $(\mathrm{t}(161,544)=10.178, \mathrm{p}<0.001)$. Figure 2 summarizes our main findings $(\mathrm{F})$.

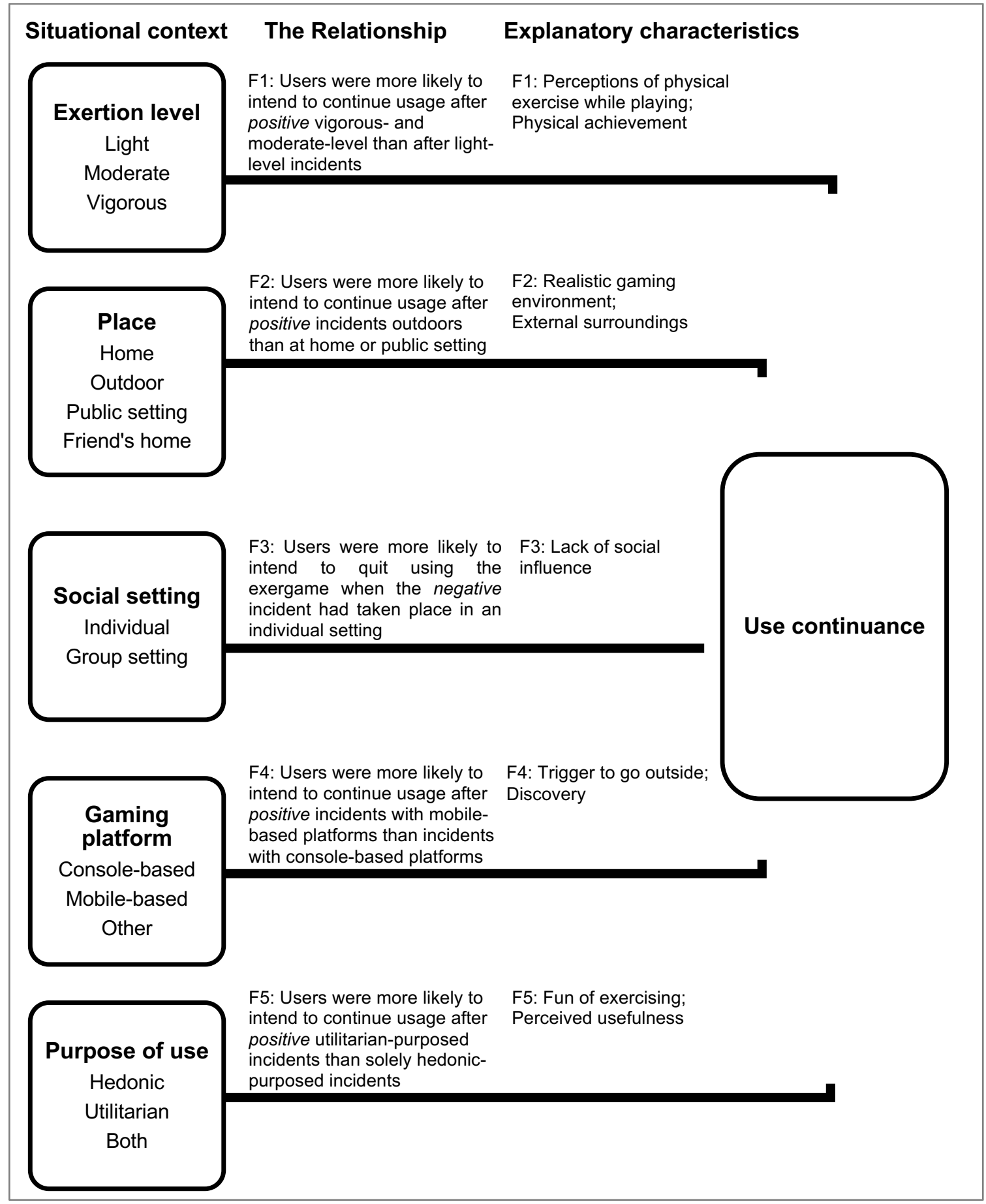

FIGURE 2 Summary of the main findings 
The statistically significant relationships with result tables, as well as their explanatory characteristics, are presented in more detail in the following subsections. Result tables in which there were no statistically significant relationships are presented in Appendix E.

\subsection{Exertion level}

In the case of positive incidents (Table 4), there was a statistically significant difference between exertion level and use continuance. Users were more likely to intend to continue usage after positive incidents at vigorous and moderate exertion levels compared to light-level incidents. In terms of exertion level and negative incidents (Appendix E), there were no statistically significant differences.

In our qualitative analysis regarding this finding (F1), we found there to be different types of characteristics between moderate-to-vigorous-level incidents and light-level incidents. Many users experienced moderate-to-vigorous-level incidents as exercise. They were not necessarily using the game mainly to exercise but rather noticed the potential of exergames in combining physical activity and gaming and getting some proper exercise while playing, as the following quote illustrates: "I realized that you can actually really exercise by playing these games and it makes you feel good." In such cases, some users also reported witnessing their own physical progression through playing the game by reaching a new physical achievement set by the game: [After reaching a physical goal] "I proved myself that my physical shape had increased and the game had been useful in exercising." This was in contrast to light-level incidents, in which the users' reports of achievements were related to an event (e.g., advancing a level, scoring points) inside the game. Also, with light-level incidents, rather few respondents mentioned the physical aspect. Instead, these incidents were more defined by spending time with friends. It seemed that the feeling of receiving proper physical exercise by playing and reaching physical achievements were the main reasons leading to positive intended use continuance.

TABLE 4 Exertion Level and Positive Incidents

\begin{tabular}{ll} 
& $\begin{array}{l}\text { Use continuance } \\
\text { Mean }(\mathrm{SD})\end{array}$ \\
\hline Light $(\mathrm{n}=140)$ & $4.07(0.86)$ \\
Moderate $(\mathrm{n}=145)$ & $4.43(0.74)$ \\
Vigorous $(\mathrm{n}=39)$ & $4.64(0.49)$ \\
Test results & ANOVA, Welch's $F(2,132.886)=15.050, \mathrm{~N}=324, p<0.001$ \\
${ }^{*} p<0.05,{ }^{* *} p<0.01,{ }^{* * *} p<0.001$ & \\
\hline
\end{tabular}

\subsection{Place}

In terms of positive incidents (Table 5), there was a statistically significant difference between place and use continuance. Users were more likely to intend to continue usage after positive 
incidents that had taken place outdoors (e.g., in nature or in a city) compared to incidents at own home or in a public setting (e.g., at school or at a fitness center). In the case of place and negative incidents (Appendix E), there were no statistically significant differences.

Regarding this finding (F2), we found in our qualitative analysis that the users' positive outdoor incidents were in many cases described by the immersion brought about by the realistic (real-world) gaming environment: "How well the dark forests (reality) suited the gaming world" [caused the positivity]. This also made the users put more physical effort into the gaming and made them engage in more physical activity than they had planned. This made the session feel more rewarding. With some of the outdoor incidents, users mentioned enjoying being able to play outdoors in nature and get some fresh air: "I was able to move and play outdoors in fresh weather." It seemed that these outdoor-specific aspects (i.e., a realistic gaming environment and external surroundings) lead to intended use continuance.

TABLE 5 Place and Positive Incidents

\begin{tabular}{ll} 
& $\begin{array}{l}\text { Use continuance } \\
\text { Mean }(\mathrm{SD})\end{array}$ \\
\hline Home $(\mathrm{n}=221)$ & $4.27(0.76)$ \\
Outdoor $(\mathrm{n}=29)$ & $4.74(0.44)$ \\
Public setting $(\mathrm{n}=36)$ & $3.95(1.08)$ \\
Friend's home $(\mathrm{n}=45)$ & $4.38(0.74)$ \\
Test results & ANOVA, Welch's $F(3,76.907)=9.551, \mathrm{~N}=331, p<0.001$ \\
${ }^{*} p<0.05,{ }^{* *} p<0.01,{ }^{* * *} p<0.001$ & \\
\hline
\end{tabular}

\subsection{Gaming platform}

For the positive incidents (Table 6), there was a statistically significant difference between gaming platform and use continuance. Users were more likely to intend to continue usage after positive incidents when they had played using a mobile-based platform compared to incidents when using a console-based platform. Concerning the gaming platform and negative incidents (Appendix E), there were no statistically significant differences.

Regarding this finding (F4), as all the positive mobile-based incidents took place in an outdoor setting, the recurring themes were rather similar to those of the positive outdoor incidents. However, in our qualitative analysis, we discovered that some themes were more likely to be connected to the mobile nature of the game than to the place. Some users reported that it was actually the game itself that triggered them to go outside in the first place: "The game made me go outside despite the cold weather and late hour." Another distinctive mobile characteristic was the fact that the game led some users to discover previously unknown areas and great views while playing: "I discovered new living and nature areas that were previously unknown to me." It seemed that the trigger to go outside and the discovery had such a positive impact on the users that they intended to continue usage. 
TABLE 6 Type of Gaming Platform and Positive Incidents

\begin{tabular}{ll} 
& $\begin{array}{l}\text { Use continuance } \\
\text { Mean }(\mathrm{SD})\end{array}$ \\
\hline Console-based $(\mathrm{n}=286)$ & $4.25(0.81)$ \\
Mobile-based $(\mathrm{n}=24)$ & $4.75(0.37)$ \\
Other $(\mathrm{n}=20)$ & $4.37(0.70)$ \\
Test results & ANOVA, Welch's $F(2,38.206)=15.272, \mathrm{~N}=330, p<0.001$ \\
${ }^{*} p<0.05,{ }^{* *} p<0.01,{ }^{* * *} p<0.001$ & \\
\hline
\end{tabular}

\subsection{Purpose of use}

In the case of positive incidents (Table 7 ), there was a statistically significant difference between purpose of use and use continuance. Users were more likely to intend to continue usage after positive incidents if the main purpose of use was either completely utilitarian or had simultaneously both utilitarian and hedonic use purposes compared to incidents with solely hedonic use purposes. In terms of the purpose of use and negative incidents (Appendix E), there were no statistically significant differences.

In our qualitative analysis regarding this finding (F5), we found that many users highlighted the fun part of exergaming even when the use purpose had been completely or partly utilitarian. However, distinct from solely hedonic-purposed incidents, users reported that exercising was fun: "Exergames can make exercising more fun and increase the motivation towards exercise," whereas, with hedonic incidents, users reported that the gaming was fun. Also, with solely hedonic-purposed incidents, having fun with others was much more present in the descriptions. Another contrast between utilitarian- and solely hedonic-purposed incidents was that, with utilitarian-purposed incidents, many users described perceiving exergaming as a way to do proper exercise that had positive effects on their physical ability: "Realizing that exercising with the game had worked and my fitness had improved." It seemed that this combination of perceived usefulness and fun of exercising was the main reason why users were more likely to intend to continue usage after incidents with completely utilitarian or simultaneously both utilitarian and hedonic use purposes.

TABLE 7 Purpose of Use and Positive Incidents

\begin{tabular}{ll} 
& $\begin{array}{l}\text { Use continuance ** } \\
\text { Mean }(\mathrm{SD})\end{array}$ \\
\hline Hedonic $(\mathrm{n}=231)$ & $4.20(0.84)$ \\
Utilitarian $(\mathrm{n}=18)$ & $4.67(0.49)$ \\
Both $(\mathrm{n}=82)$ & $4.46(0.66)$ \\
Test results & ANOVA, Welch's $F(2,51.990)=8.569, \mathrm{~N}=331, p=0.001$ \\
${ }^{*} p<0.05,{ }^{* *} p<0.01,{ }^{* * *} p<0.001$ & \\
\hline
\end{tabular}




\subsection{Social setting}

In terms of the negative incidents (Table 8), there was a statistically significant difference between social setting and use continuance. Users were more likely to intend to quit using the related exergame when the negative incident had taken place in an individual setting (i.e., the player had played alone) compared to incidents in a group setting. In terms of social setting and positive incidents (Appendix E), there were no statistically significant differences.

In our qualitative analysis regarding this finding (F3), we did not identify any materially distinct characteristics of the negative incidents between individual and group settings. The recognized tendencies were rather similar regardless of the social setting. We found that, with negative incidents, bad functionality was the most common cause of the negativity of the experience. However, it seemed that when a negative incident occurred in a group setting, it diminished the significance of the incident to the user, and the resulting feeling was less negative. While no participant explicitly indicated the cause, there could be several reasons for this, for example, social coping, social support, and conformity, which all relate to social influence, or, in the case of the individual setting, a lack of social influence. In addition, it seemed that when alone, users may engage in some post-experience behavior that would probably not occur when they are with other people, as the following quote illustrates: "I got angry when I played badly and broke the balance board by jumping on it."

TABLE 8 Social Setting and Negative Incidents

\begin{tabular}{ll} 
& $\begin{array}{l}\text { Use continuance * } \\
\text { Mean }(\mathrm{SD})\end{array}$ \\
\hline Individual $(\mathrm{n}=61)$ & $2.66(1.42)$ \\
Group setting $(\mathrm{n}=66)$ & $3.19(1.39)$ \\
Test results & $t(125)=-2.128, \mathrm{~N}=127, p=0.035$ \\
${ }^{*} p<0.05,{ }^{* *} p<0.01,{ }^{* * *} p<0.001$ & \\
\hline
\end{tabular}

\section{DISCUSSION}

The present study provides a twofold contribution. First, our study extends the current understanding of IS use continuance by investigating the role of situational context in postexperience use continuance. Second, we contribute to exergaming research by providing a first understanding of the previously unmapped area of how users behave situationdependently after critical exergaming incidents. Focusing on the context of exergaming, our study also addresses the calls for IS research on digital games and extends the studies examining digital games as IS. Thus, in addition to addressing the prevalent gaps in research on IS use continuance, we strengthen the link between IS research and digital games. We elaborate on these contributions as follows. 


\subsection{Contributions to research}

First, the present study contributes to IS use continuance research by revealing the relationships between situational context and use continuance after critical incidents. Overall, previous studies have shown that situational context can be important for IS use continuance. However, in many studies on use continuance, situational context has been investigated on a rather abstract level, for example, by merging distinct situational characteristics into one overall "use context" construct. Our efforts to open up such an abstract construct into various detailed characteristics enables researchers and practitioners to understand the role of specific situational settings that can crucially steer human behavior.

To address this point, we contribute by uncovering important relationships between specific situational characteristics and IS use continuance after critical incidents. Understanding such specific relationships assists researchers in zooming in on the complex uses of IS that occur in a great variety of use contexts. This way, we provide insights for understanding the use of ubiquitous IS (Yoo, 2010) that are widely used in various situational contexts. In addition, our study identifies a new unique characteristic-exertion level—which is a highly important aspect of exergames and other IS, such as sports technology and different wearables, that can be used with a great variety of exertion levels. The introduction of exertion level provides an extension to previous frameworks.

In contrast to premises and assumptions applied in many previous studies on IS usage and use continuance, we found that the relationships are not symmetric (e.g., place was associated with use continuance when the incident was positive but not when it was negative). Based on our findings on the asymmetric role of relationships, we encourage researchers focusing on IS usage to acknowledge and consider this duality in their future studies. These findings further support the selection of specific research methods such as CIT, as we were able to elicit results that would have remained uncovered had there been no distinction between positive and negative incidents.

Second, the present study contributes to exergaming research by providing a first insight on the previously unexplored area of how users behave situation-dependently after critical exergaming incidents. Based on our data, we present four propositions about the relationships between five situational characteristics and use continuance after critical exergaming incidents.

The first proposition is about exertion level. We found that users were more likely to intend to continue usage after positive moderate-to-vigorous-level incidents compared to lightlevel incidents. In the case of exergaming, the feelings of getting proper physical exercise by playing and reaching some physical achievement through playing were noticeably essential. As this is the first study to investigate how exertion level relates to IS use continuance, our findings provide a good starting point when researchers frame future studies concerning 
exertion level as the user's situational state with exergaming or other IS. Millions of people have recently adopted IS products and services for physical activity, exercise, and selftracking. For example, the use of smartwatches (e.g., the Apple Watch) and different wearables is becoming increasingly popular and can include use situations with different exertion levels. As exertion level is something that existing IS theories have not considered, this can be seen as a contribution both to IS research and the exergaming literature. Regarding exertion level, we propose the following:

Proposition 1: Users are more likely to continue use after positive moderate-to-vigorous level critical incidents than after positive light-level incidents, because of perceptions of getting proper physical exercise and reaching some physical achievement through playing.

Second, the ubiquitous nature of exergames and the fact that their use can occur in several different locations make place an important characteristic to investigate. Few previous studies have investigated place together with IS use continuance. Our findings provide completely new knowledge regarding exergaming, and at the same time, they extend the findings of previous studies on place and IS usage. We found that users were more likely to intend to continue usage after positive incidents that had taken place outdoors compared to incidents in their own home or in a public setting. As for exergaming, the realistic gaming environment and external surroundings were noticeably important.

Regarding the type of gaming platform used, which also relates to place, we found that users were more likely to intend to continue usage after positive incidents on a mobile-based platform compared to incidents on a console-based platform. Previous studies have also identified the technology platform and device to influence IS use. Our findings deepen this previous understanding by demonstrating the difference between console-based (i.e., stationary) and mobile-based technologies and by providing an explanation for this. The ability of mobile exergames to trigger a user to go outside and the discovery of new areas while using mobile exergames do increase users' intention to continue usage. This highlights the ubiquitous nature of mobile exergames and its importance. However, due to the correlation found in the data, we currently cannot fully disentangle the characteristics of playing exergames outdoors and using a mobile-based gaming platform. Thus, regarding place and type of gaming platform, we propose the following:

Proposition 2: Users are more likely to continue use after positive critical incidents that take place outdoors and on a mobile-based platform than after positive incidents that take place in their own home or in a public setting or on a console-based platform, because of the realistic 
gaming environment and external surroundings and because mobile exergames act as a trigger to go outside and enable the discovery of new areas.

Third, previous studies on both exergaming and IS in general have identified the importance of social setting in IS usage. However, research on its role in use continuance is limited and contradictory. We extend previous knowledge by revealing the relationship between social setting and use continuance after critical exergaming incidents. In line with some previous studies, we also found the social setting to be important, as users were more likely to intend to quit usage when the negative incident had taken place in an individual setting compared to a group setting. Although contradicting findings have also been reported (Salo \& Frank, 2017), our results suggest that social setting does indeed matter in the context of exergames. Furthermore, previous research has shown that, in contrast to individual gaming, social gaming can lead to more positive experiences, less mental tension (Gajadhar, De Kort, \& IJsselsteijn, 2008; Marker \& Staiano, 2015), and less frustration (Mandryk, Atkins, \& Inkpen, 2006). Regarding social setting, we propose the following:

Proposition 3: Users are more likely to discontinue use after negative critical incidents that take place in an individual setting than after negative incidents involving other people, because of the lack of social influence during the experience.

Fourth, we found that users were more likely to intend to continue usage after positive incidents where the main purpose of use was either completely utilitarian or had simultaneously both utilitarian and hedonic use purposes compared to incidents with solely hedonic use purposes. A combination of perceived usefulness and the fun of exercising was seemingly the main reason behind this. Previous studies have also found the purpose of use to be an influential characteristic regarding IS use. However, in most studies, the purpose of use has been divided between only hedonic and utilitarian purposes, without taking into account that some IS can be used for both hedonic and utilitarian purposes simultaneously. Notable exceptions to this are the studies by Hong and Tam (2006) and Wu and Lu (2013), which are two of the few to research the dual-purposed use of IS. By examining not only hedonic or utilitarian use but also simultaneous dual-purposed use, our study provides muchneeded insight to this area by complementing the valuable findings of Hong and Tam (2006) and Wu and Lu (2013) and extending the findings of most previous studies. We suggest that such simultaneous dual-purposed use should indeed be considered in future studies that examine the purpose of IS use. Regarding purpose of use, we propose the following: 
Proposition 4: Users are more likely to continue use after positive critical incidents with utilitarian use purposes than after positive incidents with solely hedonic use purposes, because of a combination of perceived usefulness and the fun of exercising.

The context specificity of the propositions matches the calls for heavily contextualized IS research due to its potential in generating detailed and accurate findings, offering insights for practice, extending previous theories, and decreasing the gap between general theories and specific instantiations of actual IS use in real-world settings.

The present findings may also be used to explain the popularity of the Pokémon GO exergame. We suggest that part of its popularity could be due to the following aspects: (1) people perceive they are getting physical exercise while playing and can see their physical achievements (covered kilometers) in the game, (2) users are immersed in the realistic (realworld) gaming environment of the game and enjoy the opportunity to play outdoors, (3) the game triggers users to go outside and enables the discovery of interesting locations, (4) users appreciate not having to play alone and the possibility of socializing while playing the game, and $(5)$ the game makes exercising more fun and is perceived as a useful form of exercise.

\subsection{Practical implications}

As our main practical contribution, we propose implications for exergame providers and designers by suggesting different actions and aspects that are valuable to consider in the design and development process. We also highlight the incident types that are particularly meaningful for users and provide suggestions for how providers and designers could achieve or avoid such incidents. These implications can be beneficial to and utilized by not only exergame providers but also others designing and developing IS. As our findings seem to be able to explain and resonate well the popularity of Pokémon GO, the following implications are relevant for designers and providers of exergames and other IS.

From a practical standpoint, the findings regarding exertion level suggest that exergames should provide sufficient physical challenges, which could support the need for competence (i.e., experiencing mastery and control over the presented physical challenge). Thus, designers should implement exergames with goals and achievements that are related to physical activity, not just game play. Also, highlighting the event of goal achievement could further prompt positive feelings among users. These actions could promote those influential positive moderate-to-vigorous-level incidents.

Concerning place, consumers would welcome exergames that can be played outdoors. Therefore, designing exergames that use real-world places and outdoor surroundings as the game world, for example through augmented reality, could well lead to the "next big thing" in mobile gaming. These outdoor games would require the gaming platform 
to be mobile. Also, making the gaming area as big as feasible and allowing the player to freely roam there could increase the chances of the user to experience the discovery of previously unknown areas and interesting locations. Making design decisions with these things in mind could promote influential positive incidents and support the need for autonomy (i.e., experiencing volition and agency). The users also reported that the mobile exergame itself had triggered them to go outside and play in the first place and that immersion in a realistic outdoor environment made them engage in more physical effort and activity than they had planned. These kinds of descriptions would be beneficial for marketing actions. In addition, the relatively easy distribution of mobile games and the recent growth in the mobile-gaming market highlight the market potential of mobile exergames. Thus, we encourage designers to design mobile outdoor exergames. Mobile-based exergames that can be played outdoors could also be used by different authorities to motivate people toward physical exercise.

The social setting of gaming is something that developers can affect by implementing multiplayer modes or suggesting that the game be played with others. This would promote playing in a group setting and support the need for relatedness (i.e., experiencing social connectedness to others). Also, as group settings seem to diminish the significance of negative incidents to the user, perhaps through social support or social coping, it might be a good idea to allow the user to send feedback directly from the in-game menu. In any case, regardless of the social setting, bad functionality was the most common cause of negativity in an experience. Therefore, in order to avoid users experiencing negative incidents, developers should pay extra attention to product testing before launching the game in the market, especially with single-player games. Also, regarding the fact that $44.3 \%$ of all the negative critical incidents led to discontinuance with the related exergame, developers should aim to ensure users avoid these negative incidents with their games.

Utility and entertainment form two of the most interesting aspects of exergaming and link them to dual-purposed IS. The users highlighted the ability of exergames to make exercising fun, highly valuing the fun aspect even when the use had a utilitarian purpose. Thus, exergames that are mainly meant for exercising should also be designed to be fun to play. Additionally, exergames that are mainly meant to meet hedonic needs should also somehow present the physical benefits of playing to the user, thus waking perceptions of the utilitarian benefit. It is important that the user perceives the use of the exergame to be valuable for exercise purposes. Thus, games mainly meant for exercising should provide an adequate level of physical activity and present the development of the player's physical fitness. This could be done, for example, by implementing dynamic skill levels or providing short- and longterm feedback on the player's fitness through different measures.

To sum up, by deriving from our findings and implications regarding critical incidents in different situational contexts, IS designers can transfer our findings to actual IS design 
actions. Exergame providers and designers can benefit from using our findings in developing better and more captivating exergames that achieve commercial success, will be played for a longer time, and match both the hedonic and utilitarian needs of the users. Our study also provides information that various stakeholders can benefit from in planning how exergames and other IS can be more efficiently used for positive purposes in different sectors of society.

\subsection{Limitations}

We consider the present study to have four notable limitations. First, because the information about context can, in theory, be limitless (Chávez et al., 1999), it is not possible to include an all-inclusive selection of situational characteristics. Thus, we do not claim that we have investigated a complete set of characteristics. However, based on previous literature on situational context and exergaming, we consider the selected characteristics to include the most essential ones. Yet, as technologies develop, new characteristics might emerge that complement our set. Second, despite the many strengths of the CIT, it also has some limitations (Bitner et al., 1990; Gremler, 2004). Essentially, it collects only outstanding incidents instead of ordinary experiences. However, our focus was specifically set on critical incidents, which are assumed to be more influential than ordinary ones (Flanagan, 1954; Gremler, 2004). Additionally, as the incidents reported had taken place at some point before the collection of the data, there is a risk of recall and reinterpretation bias (Folkman \& Moskowitz, 2004). The reporting of critical behaviors, however, is considered more accurate than reporting of ordinary behaviors (Andersson \& Nilsson, 1964; Gogan et al., 2014). To minimize recall and reinterpretation bias, we encouraged the respondents to take some time to recall the incident properly and then describe it in as much detail as possible. Overall, we estimated that the benefits of using the CIT in our study outweighed its limitations.

Third, the number of positive incidents (331) clearly outnumbered the number of negative incidents (130). In particular, a few of the negative incident categories included a relatively small number of cases (e.g., the category "other" in the type of gaming platform category), which may limit the generalization of the findings for those particular categories. However, the number of negative incidents collected allowed us to run the chosen statistical analyses, and the selected analysis method takes this into account. Had there been more cases, particularly in the negative incident categories, we might have been able to find a few more statistically significant relationships. Thus, future research could benefit from focusing on negative incidents in particular. Fourth, given the strong correlation between the characteristics "mobile" (gaming platform) and "outdoor" (place), we currently cannot fully disentangle the two, and one should interpret any analyses that use these two category indicators with caution. Nevertheless, given that we did not use these indicators alone, but as part of the categorical variables that were only weakly or moderately associated, we do not 
consider this to be a major problem in the analysis. Despite the limitations, the findings and implications of our study bring valuable new knowledge to the underlying research field and can be used by various stakeholders operating in gaming-, health-, and IS-related industries.

\subsection{Future research}

The present study extends previous studies associating digital games as IS and thus provides ground for future IS research on digital games. Our present findings provide several new paths for future research. For one, as we uncovered several significant relationships between specific situational characteristics and use continuance, future research can now focus on the nature of particular relationships and the underlying contextual characteristics. Considering the conceptual overlap between mobile-based and outdoor exergames, future research should focus on disentangling the place and type of gaming platform in more detail. In addition, considering the findings about the asymmetric role of relationships, researchers focusing on IS use should acknowledge and consider this duality in their future studies. Another potential approach would be to investigate the relationships between situational context and other postexperience behaviors related to exergaming (e.g., switching and word-of-mouth) in addition to use continuance. One could also choose a specific type of exergame or another type of IS artifact for closer investigation.

As we also presented the wide diversity of studies concerning exergaming across different disciplines and highlighted some prevalent research gaps, researchers can now focus on those less-studied aspects of exergaming. In particular, the IS research on exergaming is limited to date, and thus, it would be valuable to conduct more research on exergames as IS. For example, inspired by the study by Bødker, Gimpel, and Hedman (2014), we suggest studying exergames by applying the time-in/out concept to investigate how exergames are used in daily life and how the socio-material relationship evolves over time. Another future IS research direction could be to investigate the evolving exergame use through technology life narratives, as exemplified by Hedman et al. (2018). Drawing from our present findings, future research could focus on investigating how to deliberately create critical incidents that positively influence use continuance. For example, one could examine the nuances that arouse the feeling that the in-game world matches the physical world. A different, but potentially valuable, research direction could be to concentrate on how to implement these findings in the actual design and development process of exergames.

Another interesting research approach would be to investigate how game design and aesthetics influence exergame use, experience, and playing motivations by utilizing, for example, the unified theory of digital games proposed by Ralph and Monu (2015) or the works of Hunicke, LeBlanc, and Zubek (2004) and Przybylski, Rigby, and Ryan (2010). Potentially, our qualitative findings could provide a starting point for this. Przybylski et al. (2010) proposed 
that digital games have the potential to motivate and engage players by providing them with experiences that can satisfy the universal needs for competence, autonomy, and relatedness. Such experiences are likely to lead to positive outcomes, whereas if the gaming experience undermines these needs, it can lead to negative outcomes (Przybylski et al., 2010). These needs for competence, autonomy, and relatedness may also be supported by game mechanics - that is, the elements used by game developers (Ralph \& Monu, 2015) with which the player interacts. Ralph and Monu (2015) state that the digital game experience emerges from the player interacting with game artifacts (including game mechanics), which creates a positive or a negative experience. Game experiences, in contrast, "produce aesthetics," which they define as "the emotions evoked by the game." Thus, aesthetics are related to the player's internal interpretation of the game experience and might continue to last within the player's mind even after the game experience has ended (Ralph \& Monu, 2015). Ralph and Monu present nine aesthetics, eight of which were originally identified by Hunicke et al. (2004): sensation, fantasy, narrative, challenge, fellowship, discovery, expression, submission, and competition. Such aesthetics could be reflected in our present qualitative findings through the explanatory characteristics. However, studying this perspective in needed detail would require a different kind of research approach, and we open this avenue for future research.

Further, our findings could also provide insights for those investigating gamification (c.f., Deterding, Dixon, Khaled, \& Nacke, 2011; Kari, Piippo, Frank, Makkonen, \& Moilanen 2016; Koivisto \& Hamari, 2019) in different settings. Although games and gamification are different concepts, albeit with a blurry boundary (Deterding et al., 2011), our gaming and situational context-related findings could provide a starting point for those investigating the use of gamified IS implementations. Researchers could also investigate the possibilities of employing exergames in work situations, especially considering their ability to combine utilitarian and hedonic use purposes. Although their use has been studied in certain workrelated settings, such as physical education (Staiano \& Calvert, 2011), future studies could focus on, for example, how exergames could be used as tools for employee training or as part of occupational wellness programs, to increase the physical activity levels of the employees and subsequently support their well-being and work effectiveness.

\section{CONCLUSION}

This paper contributes both to the general IS continuance literature as well as to the specific area of exergaming. Use continuance is one of the central aspects to understand regarding IS use. Previous studies have shown that situational context can be important for IS use continuance but have paid limited attention to its specific characteristics. Moreover, in the area of exergaming, the link between situational context and use continuance has remained 
completely unexplored. To address these gaps, we extend current knowledge about the role of situational context in IS use continuance by uncovering and proposing how specific situational characteristics (i.e., purpose of use, gaming platform, social setting, place, exertion level) and use continuance after critical exergaming incidents are related. For example, we propose that exergame users are more likely to continue use (1) after positive moderate-tovigorous-level critical incidents than after positive light-level incidents; (2) after positive critical incidents that take place outdoors and on a mobile-based platform than after positive incidents in their own home or in a public setting or on a console-based platform; and (3) after positive critical incidents with utilitarian use purposes than after positive incidents with solely hedonic use purposes. We also propose that (4) users are more likely to discontinue use after negative critical incidents that take place in an individual setting than after negative incidents involving other people. In addition, we offer explanations for these relationships and present practical implications based on our findings.

\section{REFERENCES}

Adam, C., \& Senner, V. (2016). Which motives are predictors for long-term use of exergames?. Procedia Engineering, 147, 806-811.

Aguilar, V. S., Lamoth, C. J. C., Maurits, N. M., \& Roerdink, J. B. T. M. (2018). Assessing dynamic postural control during exergaming in older adults: A probabilistic approach. Gait \& Posture, 60, 235-240.

Altinkemer, K., \& Shen, W. (2008). A multigeneration diffusion model for IT-intensive game consoles. Journal of the Association for Information Systems, 9, 442-461.

Anderson-Hanley, C., Maloney, M., Barcelos, N., Striegnitz, K., \& Kramer, A. (2017). Neuropsychological benefits of neuro-exergaming for older adults: A pilot study of an interactive physical and cognitive exercise system (iPACES). Journal of Aging and Physical Activity, 25, 73-83.

Andersson, B., \& Nilsson, S. (1964). Studies in the reliability and validity of the critical incident technique. Journal of Applied Psychology, 48, 398-403.

Bagayogo, F. F., Lapointe, L., \& Bassellier, G. (2014). Enhanced use of IT: A new perspective on post-adoption. Journal of the Association for Information Systems, 15, 361-387.

Baranowski, T. (2017). Exergaming: Hope for future physical activity? or blight on mankind. Journal of Sport and Health Science, 6, 44-46. 
Baranowski, T., Abdelsamad, D., Baranowski, J., O’Connor, T. M., Thompson, D., Barnett, A., ... \& Chen, T. A. (2012). Impact of an active video game on healthy children's physical activity. Pediatrics, 129, e636-e642.

Baranowski, T., Maddison, R., Maloney, A., Medina E., Jr., \& Simons, M. (2014). Building a better mousetrap (exergame) to increase youth physical activity. Games for Health Journal, 3, 72-78.

Barkley, J. E., Lepp, A., \& Glickman, E. L. (2017). "Pokémon Go!” may promote walking, discourage sedentary behavior in college students. Games for Health Journal, 6, 165-170.

Barnett, A., Cerin, E., \& Baranowski, T. (2011). Active video games for youth: A systematic review. Journal of Physical Activity and Health, 8, 724-737.

Berkovsky, S., Coombe, M., Freyne, J., Bhandari, D., \& Baghaei, N. (2010, April 10-15). Physical activity motivating games: Virtual rewards for real activity. In Proceedings of the Conference on Human Factors in Computing Systems 2010 (pp. 243-252). Atlanta, GA: ACM.

Bhattacherjee, A. (2001). Understanding information systems continuance: An expectationconfirmation model. MIS Quarterly, 25, 351-370.

Bhattacherjee, A., \& Lin, C. P. (2015). A unified model of IT continuance: Three complementary perspectives and crossover effects. European Journal of Information Systems, 24, 364-373.

Bitner, M. J., Booms, B. H., \& Tetreault, M. S. (1990). The service encounter: Diagnosing favorable and unfavorable incidents. Journal of Marketing, 54, 71-84.

Bogost, I. (2005, December 1-3). The rhetoric of exergaming. In Proceedings of the Digital Arts and Cultures Conference 2005 (10 pages). Copenhagen, Denmark: IT University of Copenhagen.

Bødker, M., Gimpel, G., \& Hedman, J. (2014). Time-out/time-in: The dynamics of everyday experiential computing devices. Information Systems Journal, 24, 143-166.

Breward, M., Hassanein, K., \& Head, M. (2017). Understanding consumers' attitudes toward controversial information technologies: A contextualization approach. Information Systems Research, 28, 760-774.

Burton-Jones, A., \& Gallivan, M. J. (2007). Toward a deeper understanding of system usage in organizations: A multilevel perspective. MIS Quarterly, 31, 657-679.

Burton-Jones, A., \& Straub D. W. (2006). Reconceptualizing system usage: An approach and empirical test. Information Systems Research, 17, 228-246. 
Burton-Jones, A., \& Volkoff, O. (2017). How can we develop contextualized theories of effective use? A demonstration in the context of community-care electronic health records. Information Systems Research, 28, 468-489.

Butterfield, L. D., Borgen, W. A., Amundson, N. E., \& Maglio, A. T. (2005). Fifty years of the critical incident technique: 1954-2004 and beyond. Qualitative Research 5, 475-497.

Cenfetelli, R. T. (2004). Inhibitors and enablers as dual factor concepts in technology usage. Journal of the Association for Information Systems, 5, 472-492.

Chamberlin, B., \& Maloney, A. (2013). Active video games: Impacts and research. In K. E. Dill (Ed.), The Oxford Handbook of Media Psychology (pp. 316-333). New York: Oxford University Press.

Chávez, E., Ide, R., \& Kirste, T. (1999). Interactive applications of personal situation-aware assistants. Computers \& Graphics, 23, 903-915.

Constantiou, I. D., Lehrer, C., \& Hess, T. (2014). Changing information retrieval behaviors: An empirical investigation of users' cognitive processes in the choice of location-based services. European Journal of Information Systems, 23, 513-528.

Coursaris, C. K., \& Kim, D. J. (2011). A meta-analytical review of empirical mobile usability studies. Journal of Usability Studies, 6, 117-171.

Cui, X., Lai, V. S., \& Lowry, P. B. (2016). How do bidders' organism reactions mediate auction stimuli and bidder loyalty in online auctions? The case of Taobao in China. Information \& Management, 53, 609-624.

Davison, R. M., \& Martinsons, M. G. (2016). Context is king! Considering particularism in research design and reporting. Journal of Information Technology, 31, 241-249.

Deng, L., Turner, D. E., Gehling, R., \& Prince, B. (2010). User experience, satisfaction, and continual usage intention of IT. European Journal of Information Systems, 19, 60-75.

DeLone, W. H., \& McLean, E. R. (2003). The DeLone and McLean model of information systems success: A ten-year update. Journal of Management Information Systems, 19, 930.

Dey, A. K. (2001). Understanding and using context. Personal and Ubiquitous Computing, 5, $4-7$.

Deterding, S., Dixon, D., Khaled, R., \& Nacke, L. (2011, September 28-30). From game design elements to gamefulness: Defining gamification. In Proceedings of the 15th International Academic MindTrek Conference: Envisioning Future Media Environments (pp. 9-15). Tampere, Finland: ACM. 
Donath, L., Rössler, R., \& Faude, O. (2016). Effects of virtual reality training (exergaming) compared to alternative exercise training and passive control on standing balance and functional mobility in healthy community-dwelling seniors: A meta-analytical review. Sports Medicine, 46, 1293-1309.

Edvardsson, B., \& Roos, I. (2001). Critical incident techniques: Towards a framework for analysing the criticality of critical incidents. International Journal of Service Industry Management, 12, 251-268.

Edvardsson, B., \& Strandvik, T. (2000). Is a critical incident critical for a customer relationship?. Managing Service Quality, 10, 82-91.

Field, A. (2013). Discovering Statistics Using IBM SPSS Statistics. London: Sage.

Finco, M. D., \& Maass, R. W. (2014, May 14-16). The history of exergames: Promotion of exercise and active living through body interaction. In Proceedings of the IEEE 3rd International Conference on Serious Games and Applications for Health (pp. 1-6). Rio de Janeiro, Brazil: IEEE.

Flanagan, J. C. (1954). The critical incident technique. Psychological Bulletin, 51(4), 327-358.

Folkman, S., \& Moskowitz, J. T. (2004). Coping: Pitfalls and promise. Annual Review of Psychology, 55, 745-774.

Forbes. (2018). 'Pokémon GO' Is More Popular Than It's Been At Any Point Since Launch In 2016. Retrieved from https://www.forbes.com/sites/insertcoin/2018/06/27/pokemon-go-ismore-popular-than-its-been-at-any-point-since-launch-in-2016/.

Gabbott, M., \& Hogg, G. (1996). The glory of stories: Using critical incidents to understand service evaluation in the primary healthcare context. Journal of Marketing Management, 12, 493-503.

Gajadhar, B., De Kort, Y., \& IJsselsteijn, W. (2008, April 5-10). Influence of social setting on player experience of digital games. In Proceedings of the Extended Abstracts on Human Factors in Computing Systems 2008 (pp. 3099-3104). Florence, Italy: ACM.

Gao, Z., Zhang, T., \& Stodden, D. (2013). Children's physical activity levels and psychological correlates in interactive dance versus aerobic dance. Journal of Sport and Health Science, $2,146-151$.

Gerow, J. E., Ayyagari, R., Thatcher, J. B., \& Roth, P. L. (2013). Can we have fun@ work? The role of intrinsic motivation for utilitarian systems. European Journal of Information Systems, 22, 360-380. 
Gogan, J., McLaughlin, M. D., \& Thomas, D. (2014, December 14-17). Critical incident technique in the basket. In Proceedings of the 35th International Conference on Information Systems (17 pages). Auckland, New Zealand: AIS.

Grove, S. J., \& Fisk, R. P. (1997). The impact of other customers on service experiences: A critical incident examination of "getting along". Journal of Retailing, 73, 63-85.

Gummerus, J., \& Pihlström, M. (2011). Context and mobile services' value-in-use. Journal of Retailing and Consumer Services, 18, 521-533.

Gremler, D. D. (2004). The critical incident technique in service research. Journal of Service Research, 7, 65-89.

Hamari, J., \& Keronen, L. (2017). Why do people play games? A Meta-Analysis. International Journal of Information Management, 37, 125-141.

Hackney, R., Jones, S., \& Lösch, A. (2007). Towards an e-government efficiency agenda: The impact of information and communication behaviour on e-reverse auctions in public sector procurement. European Journal of Information Systems, 16, 178-191.

Hallal, P. C., Andersen, L. B., Bull, F. C., Guthold, R., Haskell, W., Ekelund, U., \& Lancet Physical Activity Series Working Group. (2012). Global physical activity levels: Surveillance progress, pitfalls, and prospects. Lancet, 380, 247-257.

Hedman, J., Bødker, M., Gimpel, G., \& Damsgaard, J. (2018). Translating evolving technology use into user stories: Technology life narratives of consumer technology use. Information Systems Journal, Early view, 1-23.

Hoda, M., Alattas, R., \& El Saddik, A. (2013, December 9-11). Evaluating player experience in cycling exergames. In Proceedings of the 2013 IEEE International Symposium on Multimedia (pp. 415-420). Anaheim, CA: IEEE.

Holloway, B. B., \& Beatty, S. E. (2008). Satisfiers and dissatisfiers in the online environment: A critical incident assessment. Journal of Service Research, 10, 347-364.

Hong, S., Kim, J., \& Lee, H. (2008). Antecedents of use-continuance in information systems: Toward an inegrative view. Journal of Computer Information Systems, 48, 61-73.

Hong, S. J., \& Tam, K. Y. (2006). Understanding the adoption of multipurpose information appliances: The case of mobile data services. Information Systems Research, 17, 162179.

Hong, S., Thong, J. Y., \& Tam, K. Y. (2006). Understanding continued information technology usage behavior: A comparison of three models in the context of mobile internet. Decision Support Systems, 42, 1819-1834. 
Howcroft, J., Klejman, S., Fehlings, D., Wright, V., Zabjek, K., Andrysek, J., \& Biddiss, E. (2012). Active video game play in children with cerebral palsy: Potential for physical activity promotion and rehabilitation therapies. Archives of Physical Medicine and Rehabilitation, $93,1448-1456$.

Hunicke, R., LeBlanc, M., \& Zubek, R. (2004, July 25-26). MDA: A formal approach to game design and game research. In Proceedings of the AAAI Workshop on Challenges in Game Al (pp. 1722-1726). San Jose, CA: AAAI.

Höchsmann, C., Schüpbach, M., \& Schmidt-Trucksäss, A. (2016). Effects of exergaming on physical activity in overweight individuals. Sports Medicine, 46, 845-860.

Johnston, R. (1995). The zone of tolerance: Exploring the relationship between service transactions and satisfaction with the overall service. International Journal of Service Industry Management, 6, 46-61.

Joronen, K., Aikasalo, A., \& Suvitie, A. (2017). Nonphysical effects of exergames on child and adolescent well-being: A comprehensive systematic review. Scandinavian Journal of Caring Sciences, 31, 449-461.

Jumisko-Pyykkö, S., \& Vainio, T. (2010). Framing the context of use for mobile $\mathrm{HCl}$. International Journal of Mobile Human Computer Interaction, 2, 1-28.

Junglas, I., Goel, L., Abraham, C., \& Ives, B. (2013). The Social component of information systems-How sociability contributes to technology acceptance. Journal of the Association for Information Systems, 14, 585-616.

Kari, T. (2014). Can exergaming promote physical fitness and physical activity?: A systematic review of systematic reviews. International Journal of Gaming and Computer-Mediated Simulations, 6, 59-77.

Kari, T. (2015, August 13-15). Explaining the adoption and habits of playing exergames: The role of physical activity background and digital gaming frequency. In Proceedings of the 21st Americas Conference on Information Systems (13 pages). Fajardo, Puerto Rico: AIS.

Kari, T. (2017). Promoting physical activity and fitness with exergames: Updated systematic review of systematic reviews. In B. Dubbels (Ed.), Transforming Gaming and Computer Simulation Technologies across Industries (pp. 225-245). Hershey, PA: IGI Global.

Kari, T., \& Makkonen, M. (2014, December 14-17). Explaining the usage intentions of exergames. In Proceedings of the 35th International Conference on Information Systems (18 pages). Auckland, New Zealand: AIS. 
Kari, T., Piippo, J., Frank, L., Makkonen, M., \& Moilanen, P. (2016, June 19-22). To gamify or not to gamify? Gamification in exercise applications and its role in impacting exercise motivation. In Proceedings of the 29th Bled eConference "Digital economy" (pp. 393-405). Bled, Slovenia: University of Maribor.

Klendauer, R., Berkovich, M., Gelvin, R., Leimeister, J. M., \& Krcmar, H. (2012). Towards a competency model for requirements analysts. Information Systems Journal, 22, 475-503.

Koivisto, J., \& Hamari, J. (2019). The rise of motivational information systems: A review of gamification research. International Journal of Information Management, 45, 191-210.

Krause, J. M., \& Benavidez, E. A. (2014). Potential influences of exergaming on self-efficacy for physical activity and sport. Journal of Physical Education, Recreation and Dance, 85, 15-20.

Laine, T. H., \& Suk, H. J. (2016). Designing mobile augmented reality exergames. Games and Culture, $11,548-580$.

LeBlanc, A. G., Chaput, J. P., McFarlane, A., Colley, R. C., Thivel, D., Biddle, S. J., ... \& Tremblay, M. S. (2013). Active video games and health indicators in children and youth: A systematic review. PloS ONE, 8, e65351.

Lee, I., Kim, J., \& Kim, J. (2005). Use contexts for the mobile Internet: A longitudinal study monitoring actual use of mobile internet services. International Journal of Human-Computer Interaction, 18, 269-292.

Lee, I. M., Shiroma, E. J., Lobelo, F., Puska, P., Blair, S. N., Katzmarzyk, P. T., \& Lancet Physical Activity Series Working Group. (2012). Effect of physical inactivity on major noncommunicable diseases worldwide: An analysis of burden of disease and life expectancy. Lancet, 380, 219-229.

Liang, T. P., \& Yeh, Y. H. (2011). Effect of use contexts on the continuous use of mobile services: The case of mobile games. Personal and Ubiquitous Computing, 15, 187-196.

Lieberman, D. A., Chamberlin, B., Medina, E., Franklin, B. A., Sanner, B. M., \& Vafiadis, D. K. (2011). The power of play: Innovations in getting active summit 2011 a science panel proceedings report from the American Heart Association. Circulation, 123, 2507-2516.

Limperos, A. M., \& Schmierbach, M. (2016). Understanding the relationship between exergame play experiences, enjoyment, and intentions for continued play. Games for Health Journal, 5, 100-107.

Lin, H., Wang, Y., \& Chou, C. (2012). Hedonic and utilitarian motivations for physical game systems use behavior. International Journal of Human-Computer Interaction, 28, 445-455. 
Liu, Y., \& Li, H. (2011). Exploring the impact of use context on mobile hedonic services adoption: An empirical study on mobile gaming in China. Computers in Human Behavior, 27, 890-898.

Liu, D., Li, X., \& Santhanam, R. (2013). Digital games and beyond: What happens when players compete. MIS Quarterly, 37, 111-124.

Liu, D., Santhanam, R., \& Webster, J. (2016). Towards meaningful engagement: A framework for design and research of gamified information systems. MIS Quarterly, 41, 1011-1034.

Lowry, P. B., Gaskin, J., Twyman, N., Hammer, B., \& Roberts, T. (2013). Taking 'fun and games' seriously: Proposing the hedonic-motivation system adoption model (HMSAM). Journal of the Association for Information Systems, 14, 617-671.

Lowry, P. B., Gaskin, J., \& Moody, G. D. (2015). Proposing the multi-motive information systems continuance model (MISC) to better explain end-user system evaluations and continuance intentions. Journal of the Association for Information Systems, 16, 515-579.

Lyons, E. J., Tate, D. F., Ward, D. S., Bowling, J. M., Ribisl, K. M., \& Kalyararaman, S. (2011). Energy expenditure and enjoyment during video game play: Differences by game type. Medicine and Science in Sports and Exercise, 43, 1987-1993.

Maddison, R., Simons, M., Straker, L., Witherspoon, L., Palmeira, A., \& Thin, A. (2013). Active video games: An opportunity for enhanced learning and positive health effects?. Cognitive Technology, 18, 6-13.

Maguire, M. (2001). Context of use within usability activities. International Journal of HumanComputer Studies, 55, 453-483.

Maier, C., Laumer, S., Eckhardt, A., \& Weitzel, T. (2015). Giving too much social support: Social overload on social networking sites. European Journal of Information Systems, 24, $447-464$.

Maloney, A. E., Mellecker, R., Buday, R., Gao, Z., Hinkley, T., Esparza, L., \& Alexander, S. (2015). Fun, flow, and fitness: Opinions for making more effective active videogames. Games for Health Journal, 4, 53-57.

Mandryk, R. L., Atkins, M. S., \& Inkpen, K. M. (2006, April 22-27). A continuous and objective evaluation of emotional experience with interactive play environments. In Proceedings of the Conference on Human Factors in Computing Systems 2006 (pp. 1027-1036). Montreal, Canada: ACM.

Marker, A. M., \& Staiano, A. E. (2015). Better together: Outcomes of cooperation versus competition in social exergaming. Games for Health Journal, 4, 25-30. 
Marquet, O., Alberico, C., \& Hipp, A. J. (2018). Pokémon GO and physical activity among college students. A study using ecological momentary assessment. Computers in Human Behavior, 81, 215-222.

Massad, N., Heckman, R., \& Crowston, K. (2006). Customer satisfaction with electronic service encounters. International Journal of Electronic Commerce, 10, 73-104.

Mathieson, K. (1991). Predicting user intentions: Comparing the technology acceptance model with the theory of planned behavior. Information Systems Research, 2, 173-191.

Mehrabian, A., \& Russell, J. A. (1974). An Approach to Environmental Psychology. Cambridge: MIT Press.

Menard, P., Warkentin, M., \& Lowry, P. B. (2018). The impact of collectivism and psychological ownership on protection motivation: A cross-cultural examination. Computers \& Security, $75,147-166$.

Meuter, M. L., Ostrom, A. L., Roundtree, R. I., \& Bitner, M. J. (2000). Self-service technologies: Understanding customer satisfaction with technology-based service encounters. Journal of Marketing, 64, 50-64.

Monu, K., \& Ralph, P. (2016, August 11-14). Designing the "appeal" of educational games. In Proceedings of the 22nd Americas Conference on Information Systems (9 pages). San Diego, CA: AIS.

Mueller, F., Edge, D., Vetere, F., Gibbs, M. R., Agamanolis, S., Bongers, B., \& Sheridan, J. G. (2011, May 7-12). Designing sports: A framework for exertion games. In Proceedings of the Conference on Human Factors in Computing Systems 2011 (pp. 2651-2660). Vancouver, Canada: ACM.

Mueller, F., Gibbs, M. R., Vetere, F., \& Edge, D. (2017). Designing for bodily interplay in social exertion games. ACM Transactions on Computer-Human Interaction (TOCHI), 24, 41 pages.

Mueller, F., \& Isbister, K. (2014, April 26-May 1). Movement-based game guidelines. In Proceedings of the Conference on Human Factors in Computing Systems 2014 (pp. 21912200). Toronto, Canada: ACM.

Mueller, F., Khot, R. A., Gerling, K., \& Mandryk, R. (2016). Exertion games. Foundations and Trends ${ }^{\circledR}$ in Human-Computer Interaction, 10, 1-86.

Mäyrä, F., Karvinen, J., \& Ermi, L. (2016). The Finnish Player Barometer (Report). Tampere: University of Tampere. 
Nah, F. F. H., Eschenbrenner, B., Zeng, Q., Telaprolu, V. R., \& Sepehr, S. (2014). Flow in gaming: Literature synthesis and framework development. International Journal of Information Systems and Management, 1, 83-124.

Niantic, Inc. (2016). Pokémon GO. Retrieved from http://www.pokemongo.com/

Nunnally, J. C., \& Bernstein, I. H. (1994). Psychometric Theory. New York: McGraw-Hill.

Ogawa, E. F., You, T., \& Leveille, S. G. (2016). Potential benefits of exergaming for cognition and dual-task function in older adults: A systematic review. Journal of Aging and Physical Activity, 24, 332-336.

Oh, Y., \& Oh, J. (2017). A critical incident approach to consumer response in the smartphone market: Product, service and contents. Information Systems and e-Business Management, 15, 577-597.

Ortiz de Guinea, A., \& Webster, J. (2013). An investigation of information systems use patterns: Technological events as triggers, the effect of time, and consequences for performance. MIS Quarterly, 37, 1165-1188.

Osorio, G., Moffat, D. C., \& Sykes, J. (2012). Exergaming, exercise, and gaming: Sharing motivations. Games for Health Journal, 1, 205-210.

Papastergiou, M. (2009). Exploring the potential of computer and video games for health and physical education: A literature review. Computers \& Education, 53, 603-622.

Peng, W., \& Crouse, J. (2013). Playing in parallel: The effects of multiplayer modes in active video game on motivation and physical exertion. Cyberpsychology, Behavior, and Social Networking, 16, 423-427.

Peng, W., Crouse, J. C., \& Lin, J. H. (2013). Using active video games for physical activity promotion: A systematic review of the current state of research. Health Education \& Behavior, 40, 171-192.

Przybylski, A. K., Rigby, C. S., \& Ryan, R. M. (2010). A motivational model of video game engagement. Review of General Psychology, 14, 154-166.

Ralph, P., \& Monu, K. (2015). Toward a unified theory of digital games. Computer Games Journal, 4, 81-100.

Reidsma, D., \& van Delden, R. (2018, October 4-5). Towards an interactive-movementlearning movement. In Proceedings of the 12th European Conference on Games Based Learning (pp. 532-539). Sophia Antipolis, France: ACIL.

Ribas, C. G., da Silva, L. A., Corrêa, M. R., Teive, H. G., \& Valderramas, S. (2017). Effectiveness of exergaming in improving functional balance, fatigue and quality of life in 
Parkinson's disease: A pilot randomized controlled trial. Parkinsonism \& Related Disorders, 38, 13-18.

Roto, V., Väätäjä, H., Jumisko-Pyykkö, S., \& Väänänen-Vainio-Mattila, K. (2011, September 28-30). Best practices for capturing context in user experience studies in the wild. In Proceedings of the 15th International Academic MindTrek Conference: Envisioning Future Media Environments (pp. 91-98). Tampere, Finland: ACM.

Salo, M., \& Frank, L. (2017). User behaviors after critical mobile application incidents: The relationship with situational context. Information Systems Journal, 27, 5-30.

Salo, M., Olsson, T., Makkonen, M., Hautamäki, A., \& Frank, L. (2013). Consumer value of camera-based mobile interaction with the real world. Pervasive and Mobile Computing, 9, 258-268.

Sarker, S., Xiao, X., \& Beaulieu, T. (2013). Guest editorial: Qualitative studies in information systems: A critical review and some guiding principles. MIS Quarterly, 37, iii-xviii.

Serenko, A. (2006). The use of interface agents for email notification in critical incidents. International Journal of Human-Computer Studies, 64, 1084-1098.

Serenko, A., \& Stach, A. (2009). The impact of expectation disconfirmation on customer loyalty and recommendation behavior: Investigating online travel and tourism services. Journal of Information Technology Management, 20, 26-41.

Serenko, A., \& Turel, O. (2010). Rigor and relevance: The application of the critical incident technique to investigate email usage'. Journal of Organizational Computing and Electronic Commerce, 20, 182-207.

Shaffer, J. A., DeGeest, D., \& Li, A. (2016). Tackling the problem of construct proliferation: A guide to assessing the discriminant validity of conceptually related constructs. Organizational Research Methods, 19, 80-110.

Suhonen, K., Väätäjä, H., Virtanen, T., \& Raisamo, R. (2008, October 7-9). Seriously fun: Exploring how to combine promoting health awareness and engaging gameplay. In Proceedings of the 12th International Conference on Entertainment and Media in the Ubiquitous Era (pp. 18-22). Tampere, Finland: ACM.

Staiano, A. E., Beyl, R. A., Hsia, D. S., Katzmarzyk, P. T., \& Newton Jr, R. L. (2017a). Twelve weeks of dance exergaming in overweight and obese adolescent girls: Transfer effects on physical activity, screen time, and self-efficacy. Journal of Sport and Health Science, 6, 410. 
Staiano, A. E., \& Calvert, S. L. (2011). Exergames for physical education courses: Physical, social, and cognitive benefits. Child Development Perspectives, 5, 93-98.

Staiano, A. E., Marker, A. M., Beyl, R. A., Hsia, D. S., Katzmarzyk, P. T., \& Newton, R. L. (2017b). A randomized controlled trial of dance exergaming for exercise training in overweight and obese adolescent girls. Pediatric Obesity, 12, 120-128.

Sweeney, J. C., \& Lapp, W. (2004). Critical service quality encounters on the web: An exploratory study. Journal of Services Marketing, 18, 276-289.

Tan, J., Kumar, R., \& Ralph, P. (2016, May 16). Blending immersive gameplay with intense exercise using asynchronous exergaming. In Proceedings of the 5th International Workshop on Games and Software Engineering (pp. 1-7). Austin, TX: ACM.

Taylor, M. J., \& Griffin, M. (2015). The use of gaming technology for rehabilitation in people with multiple sclerosis. Multiple Sclerosis Journal, 21, 355-371.

Thomas, D. M., \& Bostrom, R. P. (2010). Team leader strategies for enabling collaboration technology adaptation: Team technology knowledge to improve globally distributed systems development work. European Journal of Information Systems, 19, 223-237.

Thompson, D., Cantu, D., Rajendran, M., Rajendran, M., Bhargava, T., Zhang, Y., ... \& Deng, Z. (2016). Development of a teen-focused exergame. Games for Health Journal, 5, 342356.

Tobaigy, A., Alshehri, M. A., Timmons, S., \& Helal, O. F. (2018). The feasibility of using exergames as a rehabilitation tool: The attitudes, awareness, opinions and experiences of physiotherapists, and older people towards exergames. Journal of Physical Therapy Science, 30, 555-562.

Turel, O. (2015). Quitting the use of a habituated hedonic information system: A theoretical model and empirical examination of Facebook users. European Journal of Information Systems, 24, 431-446.

Turner, J. W., \& Reinsch, N. L. (2010). Successful and unsuccessful multicommunication episodes: Engaging in dialogue or juggling messages?. Information Systems Frontiers, 12, 277-285.

U.S. Department of Health and Human Services. (2008). 2008 Physical Activity Guidelines for Americans (ODPHP Publication No. U0036). Washington, DC: ODPHP.

Van der Heijden, H. (2004). User acceptance of hedonic information systems. MIS Quarterly, 24, 695-704. 
Van der Heijden, H., Ogertschnig, M., \& Van der Gast, L. (2005, May 26-28). Effects of context relevance and perceived risk on user acceptance of mobile information services. In Proceedings of European Conference on Information Systems (11 pages). Regensburg, Germany: AIS.

Van Nguyen, H., Huang, H. C., Wong, M. K., Lu, J., Huang, W. F., \& Teng, C. I. (2016). Doubleedged sword: The effect of exergaming on other forms of exercise; a randomized controlled trial using the self-categorization theory. Computers in Human Behavior, 62, 590-593.

Vatanasombut, B., Igbaria, M., Stylianou, A. C., \& Rodgers, W. (2008). Information systems continuance intention of web-based applications customers: The case of online banking. Information \& Management, 45, 419-428.

Venkatesh, V., Thong, J. Y., Chan, F. K., Hu, P. J. H., \& Brown, S. A. (2011). Extending the two-stage information systems continuance model: Incorporating UTAUT predictors and the role of context. Information Systems Journal, 21, 527-555.

Venkatesh, V., Thong, J. Y., \& Xu, X. (2012). Consumer acceptance and use of information technology: Extending the unified theory of acceptance and use of technology. MIS Quarterly, 36, 157-178.

Vodanovich, S., Sundaram, D., \& Myers, M. (2010). Research commentary-Digital natives and ubiquitous information systems. Information Systems Research, 21, 711-723.

Wakefield, R. L., \& Whitten, D. (2006). Mobile computing: A user study on hedonic/utilitarian mobile device usage. European Journal of Information Systems, 15, 292-300.

Warburton, D. E., Nicol, C. W., \& Bredin, S. S. (2006). Health benefits of physical activity: The evidence. Canadian Medical Association Journal, 174, 801-809.

Warburton, D. E., Bredin, S. S., Horita, L. T., Zbogar, D., Scott, J. M., Esch, B. T., \& Rhodes, R. E. (2007). The health benefits of interactive video game exercise. Applied Physiology, Nutrition, and Metabolism, 32, 655-663.

Whetten, D. A. (2009). An examination of the interface between context and theory applied to the study of Chinese organizations. Management and Organization Review, 5, 29-56.

Whitehead, A., Johnston, H., Nixon, N., \& Welch, J. (2010, July 28-29). Exergame effectiveness: What the numbers can tell us. In Proceedings of the 5th ACM SIGGRAPH Symposium on Video Games (pp. 55-62). Los Angeles, CA: ACM.

World Health Organization (WHO). (2010). Global Recommendations on Physical Activity for Health (Report). Geneva: WHO Press.

Wittman, G. (2010). Video gaming increases physical activity. Journal of Extension, 48, 1-4. 
Wu, J., \& Lu, X. (2013). Effects of extrinsic and intrinsic motivators on using utilitarian, hedonic, and dual-purposed information systems: A meta-analysis. Journal of the Association for Information Systems, 14, 153-191.

Yoo, Y. (2010). Computing in everyday life: A call for research on experiential computing. MIS Quarterly, 34, 213-231.

Xiao, B., \& Benbasat, I. (2011). Product-related deception in e-commerce: A theoretical perspective. MIS Quarterly, 35, 169-196.

Xie, B., Zhang, Y., Huang, H., Ogawa, E., You, T., \& Yu, L. F. (2018). Exercise intensity-driven level design. IEEE Transactions on Visualization and Computer Graphics, 24, 1661-1670.

Yang, S., Lu, Y., Gupta, S., \& Cao, Y. (2012). Does context matter? The impact of use context on mobile internet adoption. International Journal of Human-Computer Interaction, 28, 530-541.

Zeithaml, V. A., Berry, L. L., \& Parasuraman, A. (1996). The behavioral consequences of service quality. Journal of Marketing, 60, 31-46.

\section{APPENDIX A}

\section{Examples of Actual Critical Incidents (from the Empirical Data) Positive}

The user was playing a console-based dance game together with others in a home setting. The exertion level was moderate and the main purpose of use was fun.

"I got familiar with rhythm games and realized how much fun playing with dance mats can be. The low barrier to start playing and the freedom to select the skill level and the song as well as realizing I was getting some exercise without really noticing it [caused the positivity of the experience]. It was my first experience with exergames and I got so excited that I went and bought a dance mat also for myself. [As an outcome of the experience I felt] that it is nice to do exercise and gaming simultaneously (exercise in itself doesn't really inspire me)."

\section{Negative}

The user was playing a mobile-based game outdoors by himself. The user played at a vigorous exertion level for utilitarian purposes.

"I was playing the game as a part of my running exercise. In the game, you are listening the game events through headphones, and at least for me the immersion is better when I keep the volume high. Then you don't necessarily hear all the things that are happening around 
you. This one time I was running and turned straight in front of a cyclist, and we both fell down. [The negativity of the experience was caused by] me getting a shout from the cyclist. I know it was my fault. And it caused some pain I think for the both of us. Luckily neither of us got injured. Because of the experience I have not kept the volume so high anymore and it diminishes the immersion to the game. I have also become more cautious. [As an outcome of the experience I felt] frightened."

\section{APPENDIX B}

\section{Explanatory Characteristics: Categories and Descriptions Regarding Qualitative Analysis with Examples}

The related qualitative content analysis identified explanatory characteristics in the five statistically significant relationships found in the statistical analyses.

$\begin{array}{ll}\begin{array}{l}\text { Finding }(F) \text { and } \\ \text { explanatory }\end{array} & \text { Description } \\ \text { characteristics } & \end{array}$

F1: Users were more likely to intend to continue usage after positive vigorous- and moderate-level incidents than after light-level incidents

$\begin{array}{lll}\text { Physical exercise } & \begin{array}{l}\text { The user perceives getting } \\ \text { physical exercise while playing, } \\ \text { often unexpectedly. }\end{array} & \begin{array}{l}\text { "I realized that you can actually } \\ \text { really exercise by playing these } \\ \text { games and it makes you feel } \\ \text { good" }\end{array} \\ \text { Physical achievement } & \begin{array}{l}\text { The user sees the physical } \\ \text { progression through the game } \\ \text { [After reaching a physical goal] "I } \\ \text { proved myself that my physical } \\ \text { by the game. }\end{array} & \begin{array}{l}\text { shape had increased and the } \\ \text { game had been useful in } \\ \text { exercising" }\end{array}\end{array}$

F2: Users were more likely to intend to continue usage after positive incidents outdoors than at home or in a public setting

$\begin{array}{ccc}\begin{array}{c}\text { Realistic gaming } \\ \text { environment }\end{array} & \begin{array}{c}\text { The realistic gaming environment } \\ \text { immerses the user, increasing } \\ \text { effort and reward. }\end{array} & \begin{array}{c}\text { "How well the dark forests (reality) } \\ \text { suited the gaming world [caused } \\ \text { the positivity]" } \\ \text { External surroundings }\end{array} \\ \begin{array}{c}\text { The user enjoys being able to } \\ \text { "I was able to move and play } \\ \text { outdoors in fresh weather" }\end{array}\end{array}$

F3: Users were more likely to intend to quit using the exergame when the negative incident had taken place in an individual setting
Lack of social influence
The user feels the negative experience as more significant when alone.
"I got angry when I played badly and broke the balance board by jumping on it"
F4: Users were more likely to intend to continue usage after positive incidents with mobile-based platforms compared to incidents with console-based platforms
Trigger to go outside
The user is triggered by the
game to go outside and play.
"The game made me go outside despite the cold weather and late hour"
Discovery
The user discovers new interesting locations in the physical world.
"I discovered new living and nature areas that were previously unknown to me"


F5: Users were more likely to intend to continue usage after positive utilitarian-purposed incidents compared to solely hedonic-purposed incidents

Fun of exercising The user feels that the game makes exercising fun.

Perceived usefulness
The user perceives the game to be useful in exercising.
"Exergames can make exercising more fun and increase the motivation towards exercise"

"Realizing that exercising with the game had worked and my fitness had improved"

\section{APPENDIX C}

\section{Open-ended Questions Regarding Descriptions of Critical Incidents (Qualitative}

\section{Analysis)}

"Think of a time when you had an outstandingly positive or negative experience when using an exergame. Take a moment to properly recall an outstanding experience."

1. Was this a positive or a negative experience?

- Positive

○ Negative

2. The game associated with the experience:

3. Describe in as much detail as possible: what were you doing and what happened?

4. What exactly caused the positivity/negativity of the experience?

(Depending on whether the described incident was positive or negative)

5. Why do you feel that this was a significant experience for you concerning exergaming?

6. As an outcome of the experience, how did you feel?

\section{APPENDIX D}

\section{Structured Questions Regarding the Situational Characteristics (Quantitative}

\section{Analysis)}

"When the incident occurred..."

1. Did you play for fun or for exercise? (Purpose of use)

- Mainly for fun

- Mainly for exercise

- For both fun and exercise

- Cannot say

2. Did you play alone or together with other people? (Social setting)

- Alone

- Together with other people in the same physical space

- Together with other people virtually over a network 
- Cannot say

(In the analysis responses for togetherness were combined as 'Group setting')

3. At which physical exertion level did you play? (Exertion level)

- Light (no sweating or accelerated breathing)

- Moderate (some sweating and accelerated breathing)

- Vigorous (strong sweating and accelerated breathing)

- Cannot say

4. Did you play with a game console, a computer, or a mobile device (smartphone, tablet)? (Type of gaming platform)
- Game console
- Computer
- Mobile device
- Other device
- Cannot say

(In the analysis, game console and computer were combined as 'Console-based')

5. In which surrounding setting did you play? (Place)

○ Home

- Outdoor (e.g., in nature or in the city)

- Public setting (e.g., school, fitness center, hospital, etc.)

O Other, which: (open-ended)

(Before the analysis all the 'Other' responses could be categorized under existing response options and a new 'Friend's home' response)

\section{APPENDIX E}

\section{Result Tables from Quantitative Tests with No Statistically Significant Relationships}

TABLE 9 Exertion Level and Negative Incidents

\begin{tabular}{ll} 
& $\begin{array}{l}\text { Use continuance } \\
\text { Mean }(\mathrm{SD})\end{array}$ \\
\hline Light $(\mathrm{n}=54)$ & $2.97(1.28)$ \\
Moderate $(\mathrm{n}=51)$ & $2.96(1.50)$ \\
Vigorous $(\mathrm{n}=20)$ & $3.07(1.59)$ \\
Test results & ANOVA, $F(2,122)=0.043, \mathrm{~N}=125, p=0.958$ \\
${ }^{*} p<0.05,{ }^{* *} p<0.01,{ }^{* * *} p<0.001$ & \\
\hline
\end{tabular}


TABLE 10 Place and Negative Incidents

\begin{tabular}{ll} 
& $\begin{array}{l}\text { Use continuance } \\
\text { Mean }(\mathrm{SD})\end{array}$ \\
\hline Home $(\mathrm{n}=84)$ & $2.87(1.40)$ \\
Outdoor $(\mathrm{n}=22)$ & $3.09(1.64)$ \\
Public setting $(\mathrm{n}=13)$ & $2.79(1.31)$ \\
Friend's home $(\mathrm{n}=11)$ & $3.48(1.31)$ \\
\hline Test results & ANOVA, $F(3,126)=0.740, \mathrm{~N}=130, p=0.530$ \\
${ }^{*} p<0.05,{ }^{* *} p<0.01,{ }^{* * *} p<0.001$ & \\
\hline
\end{tabular}

TABLE 11 Type of Gaming Platform and Negative Incidents

\begin{tabular}{ll} 
& $\begin{array}{l}\text { Use continuance } \\
\text { Mean (SD) }\end{array}$ \\
\hline Console-based $(\mathrm{n}=96)$ & $2.91(1.36)$ \\
Mobile-based $(\mathrm{n}=24)$ & $2.92(1.66)$ \\
Other $(\mathrm{n}=7)$ & $2.95(1.47)$ \\
Test results & ANOVA, $F(2,124)=0.002, \mathrm{~N}=127, p=0.998$ \\
${ }^{*} p<0.05,{ }^{* *} p<0.01,{ }^{* * *} p<0.001$ & \\
\hline
\end{tabular}

TABLE 12 Purpose of Use and Negative Incidents

\begin{tabular}{ll} 
& $\begin{array}{l}\text { Use continuance } \\
\text { Mean (SD) }\end{array}$ \\
\hline Hedonic $(\mathrm{n}=83)$ & $2.89(1.38)$ \\
Utilitarian $(\mathrm{n}=14)$ & $2.50(1.50)$ \\
Both $(\mathrm{n}=31)$ & $3.19(1.44)$ \\
Test results & ANOVA, $F(2,125)=1.229, \mathrm{~N}=128, p=0.296$ \\
${ }^{*} p<0.05,{ }^{* *} p<0.01,{ }^{* * *} p<0.001$ & \\
\hline
\end{tabular}

TABLE 13 Social Setting and Positive Incidents

\begin{tabular}{ll} 
& $\begin{array}{l}\text { Use continuance } \\
\text { Mean (SD) }\end{array}$ \\
\hline Individual $(\mathrm{n}=69)$ & $4.45(0.65)$ \\
Group setting $(\mathrm{n}=262)$ & $4.25(0.82)$ \\
Test results & $t(329)=1.923, \mathrm{~N}=331, p=0.055$ \\
${ }^{*} p<0.05,{ }^{* *} p<0.01,{ }^{* * *} p<0.001$ & \\
\hline
\end{tabular}


APPENDIX F

Exemplar Studies of Exergaming Presenting the Wide Diversity of Exergaming Research

\begin{tabular}{|c|c|c|c|}
\hline Study & $\begin{array}{l}\text { Main related } \\
\text { research field } \\
\text { (many are } \\
\text { interdisciplinary) }\end{array}$ & $\begin{array}{l}\text { Main focus of the } \\
\text { study }\end{array}$ & $\begin{array}{l}\text { Link between } \\
\text { situational } \\
\text { context and use } \\
\text { continuance } \\
\text { studied }\end{array}$ \\
\hline Suhonen et al., 2008 & IS & Habits / experience & No \\
\hline Lin et al., 2012 & IS & Behavioral intentions & No \\
\hline Kari \& Makkonen, 2014 & IS & Usage intentions & No \\
\hline Kari, 2015 & IS & Adoption / habits & No \\
\hline Adam \& Senner, 2016 & Sports engineering & Motivations & No \\
\hline Tan et al., 2016 & Game engineering & Game Design & No \\
\hline Whitehead et al., 2010 & Computer science & Physical effects & No \\
\hline Warburton et al., 2007 & Health / exercise & Health benefits & No \\
\hline Wittman, 2010 & Health / exercise & Physical activity & No \\
\hline Barnet et al., 2011 & Health / exercise & $\begin{array}{l}\text { Physical effects / use } \\
\text { maintenance }\end{array}$ & No \\
\hline Lieberman et al., 2011 & Health / exercise & Overview & No \\
\hline Lyons et al., 2011 & Health / exercise & $\begin{array}{l}\text { Physical effects / } \\
\text { enjoyment }\end{array}$ & No \\
\hline Baranowski et al., 2012 & Health / exercise & Physical activity & No \\
\hline Howcroft et al., 2012 & Health / exercise & $\begin{array}{l}\text { Physical activity / } \\
\text { Rehabilitation }\end{array}$ & No \\
\hline Gao et al., 2013 & Health / exercise & $\begin{array}{l}\text { Comparison to other } \\
\text { forms of physical activity }\end{array}$ & No \\
\hline LeBlanc et al., 2013 & Health / exercise & Health indicators & No \\
\hline Maddison et al., 2013 & Health / exercise & Overview / health & No \\
\hline Peng et al., 2013 & Health / exercise & Physical activity & No \\
\hline Maloney et al, 2015 & Health / exercise & Overview & No \\
\hline Taylor \& Griffin, 2015 & Health / exercise & Rehabilitation & No \\
\hline Donath et al., 2016 & Health / exercise & Balance / mobility & No \\
\hline Höchsmann et al., 2016 & Health / exercise & Physical activity & No \\
\hline Ogawa et al., 2016 & Health / exercise & Treatment / cognition & No \\
\hline Thompson et al., 2016 & Health / exercise & Game design & No \\
\hline Anderson-Hanley et al., 2017 & Health / exercise & Neuropsychological & No \\
\hline Joronen et al., 2017 & Health / exercise & Nonphysical effects & No \\
\hline Ribas et al., 2017 & Health / exercise & Treatment & No \\
\hline Staiano et al., $2017 b$ & Health / exercise & Physical fitness / health & No \\
\hline Staiano et al., $2017 a$ & Health / exercise & Transfer effects & No \\
\hline Aguilar et al., 2018 & Health / exercise & Postural control & No \\
\hline Tobaigy et al., 2018 & Health / exercise & Rehabilitation attitudes & No \\
\hline Bogost, 2005 & Game studies & Rhetoric of exergaming & No \\
\hline Finco \& Maass, 2014 & Game studies & History of exergaming & No \\
\hline
\end{tabular}




\begin{tabular}{llll} 
Kari, 2014 & Game studies & Physical fitness / activity & No \\
\hline Laine \& Suk, 2016 & Game studies & Game design & No \\
\hline Osorio et al., 2012 & Psychology & Motivations & No \\
\hline Chamberlin \& Maloney, 2013 & Psychology & Physiological impacts & No \\
\hline Peng \& Crouse, 2013 & Psychology & Multiplayer modes & No \\
\hline Krause \& Benavidez, 2014 & Psychology & Self-efficacy & No \\
Marker \& Staiano, 2015 & Psychology & Social interactions & No \\
\hline Limperos \& Schmierbach, & Psychology & $\begin{array}{l}\text { Play experience / } \\
\text { enjoyment / intentions }\end{array}$ & No \\
\hline Berkovsky et al., 2010 & $\mathrm{HCl} / \mathrm{CHI}$ & Game design & No \\
\hline Hoda et al., 2013 & $\mathrm{HCl} / \mathrm{CHI}$ & Player experience & No \\
Mueller \& Isbister, 2014 & $\mathrm{HCl} / \mathrm{CHI}$ & Game design & No \\
Van Nguyen et al., 2016 & $\mathrm{HCl} / \mathrm{CHI}$ & Impact on other forms of & No \\
& & physical activity & \\
Mueller et al., 2017 & $\mathrm{HCl} / \mathrm{CHI}$ & Game design & No \\
Marquet et al., 2018 & $\mathrm{HCl} / \mathrm{CHI}$ & Physical activity & No \\
Xie et al., 2018 & $\mathrm{HCl} / \mathrm{CHI}$ & Game design & No \\
\hline
\end{tabular}

Note: Many of these studies are highly interdisciplinary so that naming the main related research field is not always unambiguous. Some also have multiple focus areas. 